\title{
On the Effects of Monetary Policy Shocks on Exchange Rates
}

\author{
Michael Binder \\ Qianying Chen \\ Xuan Zhang
}

\author{
CESIFO WORKING PAPER NO. 3162 \\ CATEGORY 7: MONETARy POLICY AND INTERNATIONAL FinANCE \\ August 2010
}

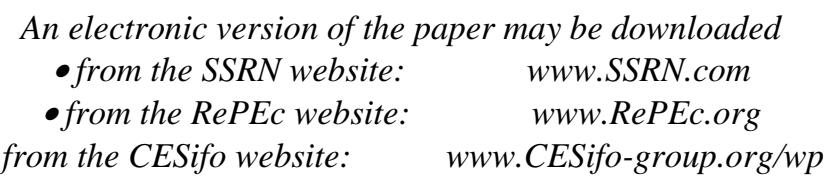




\title{
On the Effects of Monetary Policy Shocks on Exchange Rates
}

\begin{abstract}
In this paper we re-consider the effects of monetary policy shocks on exchange rates and forward premia. In the recent empirical literature, these effects have been predominantly described as puzzling, in that they would include delayed overshooting of the exchange rate as well as persistent deviations from uncovered interest parity. We specify an empirical model that in particular (i) allows for simultaneous multi-country adjustments in response to monetary policy shocks, and (ii) takes advantage of the identifying restrictions for monetary policy shocks implied by empirically supported long-run relations between the macroeconomic variables under consideration. Using monthly data from 1978 to 2006 for a panel of nine industrial economies (Australia, Canada, France, Germany, Italy, Japan, New Zealand, United Kingdom, and the United States), we find that U.S. Dollar effective and bilateral real exchange rates appreciate on impact after a contractionary U.S. monetary policy shock, and that there is no delay in the overshooting of the U.S. Dollar. Furthermore, there is no persistent significant forward premium. These results are consistent with the real exchange rate effects of monetary policy shocks in sticky price macroeconomic models, though the results of this paper also suggest that the latter models should be specified so as to capture simultaneous multi-country adjustments to shocks.
\end{abstract}

JEL-Code: C33, E52, F31.

Keywords: monetary policy, exchange rate overshooting, forward premium, global vector error correction model.

\author{
Michael Binder \\ Goethe University Frankfurt \\ Faculty of Economics and Business Administration \\ Department of Money and Macroeconomics \\ Grueneburgplatz 1 (House of Finance) \\ Germany - 60323 Frankfurt am Main \\ mbinder@wiwi.uni-frankfurt.de
}

\author{
Qianying Chen \\ Goethe University Frankfurt \\ qichen@wiwi.uni-frankfurt.de
}

\author{
Xuan Zhang \\ Goethe University Frankfurt \\ xuazhang@wiwi.uni-frankfurt.de
}

We are grateful for comments and suggestions from Don Harding, Nelson Mark and Ron Smith, as well as from seminar and conference participants at Australian National University, European Central Bank, Fundação Getulio Vargas, Goethe University Frankfurt, Hong Kong University of Science and Technology, International Monetary Fund, Notre Dame University, Reserve Bank of New Zealand, University of Bonn, University of Maastricht, University of Munich, and University of Rotterdam. 


\section{Introduction}

It has been a long-standing question in both theoretical and empirical macroeconomics how a change in a country's monetary policy affects the external value of its currency. The recent debate surrounding the International Monetary Fund's recommendation to the Central Bank of Iceland in fall of 2008 to dramatically raise interest rates in an attempt to prevent continued depreciation of the Iceland Krona is just one example highlighting the continued topicality of this question.

From the perspective of macroeconomic theory, a - if not the - key contribution towards resolution of this question still is Dornbusch's (1976) exchange rate overshooting model, predicting that in response to a contraction of domestic monetary policy, the real exchange rate - due to a liquidity effect and a no-arbitrage restriction implied by uncovered interest parity - will exhibit an impact appreciation, that is followed by a gradual depreciation. This gradual depreciation continues until the long-run equilibrium - that involves return to the original real exchange rate equilibrium in line with purchasing power parity - is reached. In the recent new open economy macroeconomics literature, the exchange rate overshooting mechanism has been re-examined on the basis of dynamic stochastic general equilibrium models that make reference to the three core components of the overshooting mechanism: a liquidity effect of monetary policy, an interest parity relation, and long-run purchasing power parity. To highlight just two contributions to this literature: Steinsson (2008) argues that in a dynamic stochastic general equilibrium model incorporating inter alia staggered price setting, local currency pricing, home biased preferences and heterogeneous factor markets, the real exchange rate exhibits peak overshooting in response to a monetary shock after one or two months, and thereafter decays exponentially, consistent with Dornbusch (1976). Bergin (2006) estimates a dynamic stochastic general equilibrium model inter alia including monopolistically competitive firms, sluggish price setting, capital accumulation subject to adjustment costs as well as a risk-premium-augmented interest parity relation, and finds that the real exchange rate exhibits impact overshooting, followed by a gradual return to long-run equilibrium. Benigno (2004) argues that the details of the dynamic adjustment pattern of the real exchange rate after a monetary policy shock depend on the relative degrees of wage/price stickiness in the domestic and foreign economies, as well as the degree of interest rate smoothing of monetary policy domestically and abroad.

The predominant strand of the empirical literature (including Clarida and Gali, 1994, Eichenbaum and Evans, 1995, Kim, 2005, and Scholl and Uhlig, 2008), on the other hand, has documented that in response to a monetary policy contraction the peak appreciation of the nominal and real exchange rates occurs with sizeable lag only, that is, the impulse response function exhibits a hump-shape pattern, the so-called "delayed exchange rate overshooting puzzle". Furthermore, the empirical evidence appears to contradict conditional uncovered interest parity, and suggests sizeable and persistent arbitrage opportunities in favor of U.S. bonds after a contractionary U.S. monetary 
policy shock, which has been termed the "forward premium/discount puzzle". ${ }^{1}$ Figure 1 illustrates the "delayed exchange rate overshooting puzzle" as well as the "forward premium puzzle". ${ }^{2}$ This empirical evidence has been viewed as so strong that in the open economy macroeconomics literature various mechanisms - such as limited information processing, distortion of beliefs, and state-dependent pricing - have been advanced that can account for the "delayed exchange rate overshooting puzzle" and/or the "forward premium puzzle"; see, for example, Gourinchas and Tornell (2004), Andersen and Beier (2005), Bacchetta and van Wincoop (2006), and Landry (2009).

The common framework of the empirical literature have been bilateral (two-country) vector autoregressions (VARs) that incorporate key macroeconomic variables for the domestic economy and one foreign economy, and that identify the exchange rate effects of a domestic monetary policy shock primarily on the basis of a Cholesky decomposition involving a Wold recursive ordering of the variables contained in the VAR. Recent empirical work employing weaker short-run identification schemes, namely sign restrictions, argues that the two puzzles are not tied to the identification of VARs using Cholesky decompositions; see, in particular, Scholl and Uhlig (2008).

In this paper, we address the question to what extent previous empirical findings suggesting the presence of a "delayed exchange rate overshooting puzzle" and a "forward premium puzzle" may have been caused by two issues: (i) Working with bilateral VARs neglects to account for multilateral (multi-country) simultaneous adjustments of key macroeconomic variables in response to monetary policy shocks in one given country - even though such multi-country adjustments seem to be an essential feature for groups of economies with sizeable multilateral trade and financial market linkages. (ii) Identifying monetary policy shocks by imposing short-run restrictions of the form of a Cholesky decomposition tends to be difficult to reconcile with macroeconomic theory, and does not take advantage of identification restrictions implied by empirically supported long-run relations between the macroeconomic variables under consideration in the VAR. ${ }^{3}$ In this paper, then, we specify a multi-country VAR model for a panel of nine industrial economies (Australia, Canada, France, Germany, Italy, Japan, New Zealand, United Kingdom, and the United States), using monthly data from 1978 to 2006. On the basis of this multi-country specification and exploiting empirically supported long-run relationships for the identification of monetary policy shocks, we find that U.S.

\footnotetext{
${ }^{1}$ The "forward premium puzzle" is separate from unconditional violations of uncovered interest parity as reviewed, for example, by Engel (1996). It is also worth noting that even papers that have argued that the "delayed exchange rate overshooting puzzle" may be sensitive to the restrictions imposed in identifying monetary policy shocks, argue that the "forward premium puzzle" is robust to identification issues and is empirically prevalent. See, for example, Faust and Rogers (2003).

${ }^{2}$ In Section 2, we will also relate our paper to previous papers in the literature, specifically Cushman and Zha (1997), Kim and Roubini (2000), and Bjornland (2009), that have argued that there is no delay of exchange rate overshooting and/or no evidence of deviations from uncovered interest parity in response to monetary policy shocks.

${ }^{3}$ The information content of long-run relations for purposes of model identification has recently been emphasized by Pagan and Pesaran (2008).
} 
Dollar effective and bilateral real exchange rates appreciate on impact after a contractionary U.S. monetary policy shock, and that there is no delay in the overshooting of the U.S. Dollar. Furthermore, after a contractionary monetary policy shock there is no persistent sizeable deviation from uncovered interest parity, and therefore no sizeable forward premium. These results are consistent with the real exchange rate effects of monetary policy shocks in sticky price open economy models, though the results of this paper also suggest that it will be insightful to extend various prominent examples of such models - including those of Benigno (2004), Bergin (2006), and Steinsson (2008) - so as to capture simultaneous multi-country adjustments to shocks.

The remainder of the paper is structured as follows: In Section 2, we review the empirical models considered in the previous literature, with particular emphasis on a benchmark model of Eichenbaum and Evans (1995). In Section 3, we provide a theoretical motivation for studying multilateral models, and then introduce our empirical multilateral model specification in Section 4. We discuss the measurement of monetary policy indicators for the nine economies we consider as well as the identification of monetary policy shocks using empirically supported long-run relations in Section 5. We present our empirical results in Section 6, and in Section 7 provide various comparisons between results from our empirical model specification and those employed in the previous literature. Section 8, finally, concludes. Two appendices contain details on the database we have assembled for this paper, as well as some tables of empirical results.

\section{Review of the Literature}

\subsection{Methodology of Eichenbaum and Evans (1995)}

Almost all of the empirical models considered in the literature to date on the "delayed exchange rate overshooting puzzle" and the "forward premium puzzle" are bilateral (two-country) vector autoregressions (VARs). ${ }^{4}$ We take one of the specifications in Eichenbaum and Evans (1995) as a benchmark. Eichenbaum and Evans (1995) use a bilateral VAR to model the bilateral relationships of key macroeconomic variables for five country pairs: the United States versus France, the United States versus Germany, the United States versus Italy, the United States versus Japan, and the United States versus the United Kingdom. For each of these five country pairs, Eichenbaum and

\footnotetext{
${ }^{4}$ This literature, as noted in the Introduction, includes Clarida and Gali (1994), Eichenbaum and Evans (1995), Cushman and Zha (1997), Kim and Roubini (2000), Faust and Rogers (2003), Kim (2005), Scholl and Uhlig (2008), and Bjornland (2009). Some of these papers also include empirical model specifications for which the "foreign country" variables are specified as weighted averages of variables across a sizeable set of foreign countries, subject to exogeneity restrictions. Such model specifications, unlike the model that we will consider in this paper, still cannot capture simultaneous multi-country adjustments, the hallmark of a genuinely multilateral model.
} 
Evans (1995) consider a VAR model of the form of

$$
\mathbf{z}_{t}=\mathbf{a}_{0}+\mathbf{a}_{1} t+\sum_{s=1}^{p} \mathbf{A}_{s} \mathbf{z}_{t-s}+\mathbf{u}_{t}, \quad \mathbf{u}_{t} \stackrel{i i d}{\sim}\left(\mathbf{0}, \Omega_{\mathbf{u}}\right),
$$

where

$$
\mathbf{z}_{t}=\left(\begin{array}{lllllll}
y_{t} & P_{t} & y_{t}^{*} & R_{t}^{*} & F F R_{t} & n b r x_{t} & q_{t}
\end{array}\right)^{\prime},
$$

with $y_{t}$ denoting U.S. real industrial production, $P_{t}$ the U.S. consumer price index, $y_{t}^{*}$ foreign real industrial production, $R_{t}^{*}$ the foreign nominal short-term interest rate (short-term money market rate), $F F R_{t}$ the federal funds rate, $n b r x_{t}$ the ratio between U.S. non-borrowed reserves and U.S. total reserves, and $q_{t}$ the bilateral real exchange rate (in units of U.S. Dollars per one unit of foreign currency). All elements of $\mathbf{z}_{t}$, except for the interest rates, are in logarithms. Eichenbaum and Evans (1995) choose the VAR lag order, $p$, across all country pairs to be equal to six for the monthly sample from 1974:1 to 1995:5 they are working with. They identify the monetary policy shock using a Cholesky decomposition involving a Wold recursive ordering of the variables (this ordering being as in Equation (2.2)), inter alia implying that the Federal Reserve sets the federal funds rate taking into account the lagged values of all the components of $\mathbf{z}_{t}$ as well as the current values of U.S. industrial production, U.S. prices, foreign industrial production, and the foreign short-term interest rate (but not the real exchange rate).

As has been widely discussed in the literature on monetary policy VARs, monetary policy shocks in VAR models measure the unexpected change in a monetary authority's monetary policy stance relative to the information set to which these shocks are orthogonal, here

$$
\mathfrak{I}_{t}=\left\{y_{t}, \quad P_{t}, \quad y_{t}^{*}, \quad R_{t}^{*} ; \quad \mathbf{z}_{t-s}, s \geq 1\right\} .
$$

Such unexpected changes can then be due to, for example, (i) discrepancies between the monetary authority's information set at $t$ and the public's information set at $t$, the latter being given by $\mathfrak{I}_{t}$, (ii) changes in the target values of the variables entering the monetary authority's monetary policy decisions, and/or (iii) changes in the parameters of the monetary authority's decision rule (for (ii) and (iii) as long as these changes are not reflected in $\mathfrak{I}_{t}$ ).

Selecting the United States versus Germany based bilateral VAR of Equation (2.1) as one representative example of the analysis of Eichenbaum and Evans (1995), Figure 2 shows the impulse responses for various key variables after a positive federal funds rate shock (that is, a contractionary U.S. monetary policy shock). ${ }^{5}$ In regards to exchange rate effects, the bilateral real exchange rate of the U.S. Dollar relative to the Deutsche Mark $\left(q^{U S D / D M}\right)$ overshoots its long-run level with a delay

\footnotetext{
${ }^{5}$ To replicate Eichenbaum and Evans (1995), the U.S. monetary policy shock for Figure 2 is set to 50 basis points. All impulse response standard error bands reported in this paper are $95 \%$ error bands, which we obtained using a bootstrapping algorithm as described in Kilian (1998).
} 
of about three years, termed the "delayed exchange rate overshooting puzzle" in the literature. The interest rate differential between the federal funds rate $(F F R)$ and the German short-term interest rate $\left(R^{D E U}\right)$ after the positive federal funds rate shock exhibits a positive difference for about 15 months. The forward premium, defined as in Scholl and Uhlig (2008) as

$$
\xi_{t}=-F F R_{t}+R_{t}^{*}+Q_{t+1}-Q_{t}
$$

(the one period ex post excess return after a contractionary U.S. monetary policy shock for a U.S. investor from borrowing U.S. Dollars, exchanging these to foreign currency at the bilateral nominal spot exchange rate, $Q_{t}$, investing in foreign short-term bonds, and then exchanging the proceeds back to U.S. Dollar after one period), ${ }^{6}$ for the United States versus Germany country pair $\left(\xi_{t}^{U S A / D E U}\right)$ in response to a federal funds rate shock deviates - partially substantially and significantly - from zero for a little more than one year, indicating sizeable arbitrage opportunities in favor of U.S. bonds. As under conditional uncovered interest parity in response to a monetary policy shock it would hold that $E_{t}\left(\xi_{t+s}\right)-E_{t-1}\left(\xi_{t+s}\right)=0, s \geq 0$, with $E_{t}(\cdot)$ denoting the conditional expectations operator, this finding is termed the "forward premium puzzle" in the literature. Finally (though not displayed in Figure 2), we can also replicate the Eichenbaum and Evans (1995) finding that the impulse responses for U.S. prices display a positive reaction to the positive federal funds rate shock, rather than following the pattern of a typical dynamic stochastic general equilibrium macroeconomic model with price stickiness, namely of initially failing to respond and after a while beginning to fall.

It should again be emphasized that the "delayed exchange rate overshooting puzzle" and the "forward premium puzzle" of Clarida and Gali (1994) and Eichenbaum and Evans (1995) have recently been re-affirmed in some key contributions to the literature; see, for example, Kim (2005) and Scholl and Uhlig (2008). Also, as noted briefly in the Introduction, this empirical evidence has been viewed as so strong that in the open economy macroeconomics literature various mechanisms - such as limited information processing, distortion of beliefs, and state-dependent pricing - have been advanced that can account for the "delayed exchange rate overshooting puzzle" and/or the "forward premium puzzle"; see, for example, Gourinchas and Tornell (2004), Andersen and Beier (2005), Bacchetta and van Wincoop (2006), and Landry (2009).

\section{$2.2 \quad$ Further Empirical Work}

There is a small number of papers in the literature to date, in particular Cushman and Zha (1997), Kim and Roubini (2000), Faust and Rogers (2003), and Bjornland (2009), that have argued that

\footnotetext{
${ }^{6}$ Note that this definition of the forward premium involving the ex post future spot exchange rate differs from that used in other areas of the international macroeconomics literature, which uses the forward exchange rate rather than the ex post future spot exchange rate.
} 
there is no empirical support for the "delayed exchange rate overshooting puzzle" and/or the "forward premium puzzle".

Cushman and Zha (1997) and Kim and Roubini (2000) consider non-U.S. monetary policy shocks. Exclusively analyzing countries that can arguably be classified as small open economies, they consider short-run monetary policy identification schemes that - unlike the Eichenbaum and Evans (1995) Cholesky decomposition based identification scheme - do allow for monetary policy to contemporaneously respond to changes in the exchange rate. Under such an identification scheme, Cushman and Zha (1997) and Kim and Roubini (2000) find no empirical support for the "delayed exchange rate overshooting puzzle" and/or the "forward premium puzzle". The analyses of Cushman and Zha (1997) and Kim and Roubini (2000) by construction are not applicable to analyzing the effects of U.S. monetary policy shocks, however, and involve short-run identifying restrictions that are rather difficult to justify on the basis of macroeconomic theory.

Faust and Rogers (2003) impose sign restrictions on the impact impulse response, and find that the exchange rate impulse response to contractionary U.S. monetary policy shocks is sensitive to additional - difficult to justify - short-run restrictions required for the identification of U.S. monetary policy shocks, with no robust conclusion about the timing of the appreciation peak after a contractionary U.S. monetary policy shock being possible. ${ }^{7}$ As argued by Scholl and Uhlig (2008), however, if one is to impose sign restrictions for the identification of the impact impulse response, one may circumvent having to impose additional - difficult to justify - short-run identifying restrictions by imposing sign restrictions not only on the contemporaneous, but also on the future effects of the shocks. Doing so, Scholl and Uhlig (2008) re-affirm the "delayed exchange rate overshooting puzzle" and the "forward premium puzzle" in response to U.S. monetary policy shocks.

Bjornland (2009), like Cushman and Zha (1997) and Kim and Roubini (2000), constructs a VAR model of a small open economy. For her VAR, Bjornland (2009) imposes the restriction that a monetary policy shock cannot have long-run effects on the level of the real exchange rate. This long-run restriction allows Bjornland (2009) to circumvent having to specify short-run restrictions on the interaction between monetary policy and the real exchange rate of the type considered by Cushman and Zha (1997) and Kim and Roubini (2000). Our approach, as we will detail in Section 5 , involves using a larger number of long-run identifying restrictions, as is implied by the empirical evidence, and thus indeed uses as few short-run identifying restrictions as possible. In contrast to Bjornland (2009), for each country we link our long-run identifying restrictions to empirical evidence on the number of long-run relations among the variables in our model. Perhaps most important in regards to comparison of our modelling approach to that of Bjornland (2009), our empirical model specification does not require a small open economy assumption, and we can therefore also consider

\footnotetext{
${ }^{7}$ As noted in the Introduction, Faust and Rogers (2003) find the "forward premium puzzle", on the other hand, to be robustly present for the complete set of short-run restrictions they consider.
} 
U.S. monetary policy shocks.

\section{Multilateral Models: Motivation}

In this Section we provide a brief theoretical motivation for working with multilateral rather than bilateral models when analyzing the exchange rate effects of monetary policy shocks. The model we will consider in this Section consider is highly stylized, isolating the instantaneous exchange rate effects of monetary policy shocks in a world of three countries as compared to a world of two countries, rather than providing an elaborate multilateral dynamic stochastic general equilibrium model that would capture the complete set of variables entering our subsequent empirical analysis.

To keep the exposition in this Section as simple as possible, we suppose that there are at most three countries, labelled as countries "0", "1", and "2". Also for simplicity, we suppose that there are at most three types of financial assets, bonds of maturity one period denominated in the currencies of country 0 , of country 1 , and of country 2, respectively. As we will consider the exchange rate effects of changes in monetary policy in country 0 , only for country 0 we distinguish between private investors and monetary authorities. For countries 1 and 2, we only model private investors. ${ }^{8}$

We will distinguish two model structures: Under model structure "Mํ., we only take into account two of the three countries, namely country 0 as the domestic economy, and the only foreign economy being given by country 1 . Under model structure " $\mathfrak{M}_{2}$ ", therefore, we drop country 2 from the analysis. Under model structure " $\mathfrak{M}_{3}$ ", we model all three countries, with country 0 again being the domestic economy, but now both country 1 and country 2 being foreign economies.

We first describe the two-country world, $\mathfrak{M}_{2}$. We have the following time $t$ equilibrium conditions for the two bonds in this model structure:

$$
B_{i 0_{p} t}+B_{i 0_{g} t}+B_{i 1 t}=0, \quad i=0,1
$$

where $B_{i 0_{p} t}$ denotes the time $t$ holdings of the bond denominated in the currency of country $i$ by the private investors in country $0, B_{i 0_{g} t}$ the time $t$ holdings of the bond denominated in the currency of country $i$ by the monetary authorities of country 0 , and $B_{i 1 t}$ the time $t$ holdings of the bond denominated in the currency of country $i$ by the investors in country 1 . Suppose that the private investors in country 0 as well as the investors in country 1 use mean-variance analysis to optimize their portfolio holdings. At the time of solving their portfolio optimization problems, the investors

\footnotetext{
${ }^{8}$ While the magnitude of the exchange rate effects of monetary policy changes in country 0 would be different if we captured that central banks in countries 1 and 2 may respond to the monetary policy changes in country 0 , our main point in this Section, namely that the exchange rate effects of monetary policy changes in country 0 will in general be mis-measured when considering a bilateral model, is not dependent on our assumption of there only being private investors in countries 1 and 2 .
} 
know the nominal rates of return on the two bonds (the nominal rate of return for country $i$ from $t$ to $t+1$ being denoted by $R_{i t}$ ), but face uncertainty regarding the one-period-ahead spot exchange rate between country 0 and country 1 , and the one-period-ahead prices in both countries. The portfolio optimization problem of the private investors in country 0 is then given by:

$$
\max _{\left.\omega_{10_{p} t}\right|_{\mathfrak{M}_{2}}}\left\{E_{t}\left(\left.\rho_{0_{p} t}\right|_{\mathfrak{M}_{2}}\right)-\frac{1}{2} \gamma_{0_{p}} \operatorname{Var}_{t}\left(\left.\rho_{0_{p} t}\right|_{\mathfrak{M}_{2}}\right)\right\}
$$

$\left.\omega_{10_{p} t}\right|_{\mathfrak{M}_{2}}$ denoting the weight (under model structure $\mathfrak{M}_{2}$ ) in the time $t$ portfolio of the private investors in country 0 of the bonds denominated in the currency of country $1,\left.\rho_{0_{p} t}\right|_{\mathfrak{M}_{2}}$ denoting the real rate of return from $t$ to $t+1$ on the portfolio of the private investors in country 0 (under model structure $\left.\mathfrak{M}_{2}\right), \gamma_{0_{p}}$ denoting the coefficient of risk aversion of the private investors in country 0 , and $\operatorname{Var}_{t}(\cdot)$ denoting the conditional variance operator at time $t$, with

$$
\rho_{0_{p} t}=\left(1-\left.\omega_{10_{p} t}\right|_{\mathfrak{M}_{2}}\right)\left(R_{0 t}-\pi_{0, t+1}\right)+\left.\omega_{10_{p} t}\right|_{\mathfrak{M}_{2}}\left(R_{1 t}+\psi_{01, t+1}-\pi_{0, t+1}\right),
$$

and with $\pi_{0, t+1}$ denoting the rate of inflation in country 0 at time $t+1, \psi_{01, t+1}$ the rate of appreciation of the currency of country 1 against the currency of country 0 from $t$ to $t+1$, and

$$
\left.\omega_{10_{p} t}\right|_{\mathfrak{M}_{2}}=\frac{Q_{01 t} B_{10_{p} t}}{B_{00_{p} t}+Q_{01 t} B_{10_{p} t}}
$$

$Q_{01 t}$ denoting the time $t$ nominal spot exchange rate between countries 0 and 1 (measured as units of currency of country 0 per one single unit of currency of country 1 ). Finally, we suppose that

$$
\begin{gathered}
E_{t}\left(\pi_{0, t+1}\right)=\mu_{\pi_{0} t}, \quad \operatorname{Var}_{t}\left(\pi_{0, t+1}\right)=\sigma_{\pi_{0}}^{2}, \\
E_{t}\left(\psi_{01, t+1}\right)=\mu_{\psi_{01} t}, \quad \operatorname{Var}_{t}\left(\psi_{01, t+1}\right)=\sigma_{\psi_{01}}^{2},
\end{gathered}
$$

and

$$
\operatorname{Cov}_{t}\left(\pi_{0, t+1}, \psi_{01, t+1}\right)=\sigma_{\pi_{0}, \psi_{01}}
$$

Note that for simplicity of exposition we do not specify the dependence of the first and second moments in (3.5) to (3.7) on underlying macroeconomic and financial market fundamentals. While such specification would be essential for an analysis characterizing the complete time path of the exchange rates, our focus here is on the time $t$ appreciation of the currency of country 0 in response to a contractionary change of the monetary policy stance in country 0 within the two-country model, in contrast to what it would be in a three-country model to be analyzed below. For this purpose, little is to be gained from specifying how the first and second moments in (3.5) to (3.7) depend on macroeconomic and financial market fundamentals. 
Solving the optimization problem given by (3.2) to (3.7), it is readily established that the time $t$ optimal portfolio share of the bond denominated in the currency of country 1 by the private investors in country 0 under model structure $\mathfrak{M}_{2}$ is given by

$$
\left.\omega_{10_{p} t}\right|_{\mathfrak{M}_{2}}=\frac{R_{1 t}+\mu_{\psi_{01} t}-R_{0 t}}{\gamma_{0_{p}} \sigma_{\psi_{01}}^{2}}+\frac{\sigma_{\pi_{0}, \psi_{01}}}{\sigma_{\psi_{01}}^{2}} .
$$

From (3.8), the optimal portfolio share under model structure $\mathfrak{M}_{2}$ of the bond denominated in the currency of country 1 for the private investors in country 0 is a function (i) of the risk-adjusted excess rate of return of the bond denominated in the currency of country 1 compared to the bond denominated in the currency of country 0 , as well as (ii) the hedge the bond denominated in the currency of country 1 provides against inflation in country 0.

Let us now turn to the three-country world, $\mathfrak{M}_{3}$. For the three-country world, we extend the time $t$ equilibrium conditions in Equation (3.1) to reflect that the bonds denominated in the currencies of countries 0 and 1 can also be held by the investors in country 2 , and to incorporate the time $t$ holdings of the bond denominated in the currency of country $2, B_{i 2 t}$ :

$$
B_{i 0_{p} t}+B_{i 0_{g} t}+B_{i 1 t}+B_{i 2 t}=0, \quad i=0,1,2
$$

We suppose that beyond the private investors in country 0 and the investors in country 1 , the investors in country 2 also use mean-variance analysis to optimize their portfolio holdings. Mirroring the set-up of the two-country model, at the time of solving their portfolio optimization problems, the investors know the nominal rates of return on the three bonds, but face uncertainty regarding the set of one-period-ahead spot exchange rates and the one-period-ahead prices in all three countries. The portfolio optimization problem of the private investors in country 0 is now given by:

$$
\max _{\left.\omega_{10_{p} t}\right|_{\mathfrak{M}_{3}},\left.\omega_{20_{p} t}\right|_{\mathfrak{M}_{3}}}\left\{E_{t}\left(\left.\rho_{0_{p} t}\right|_{\mathfrak{M}_{3}}\right)-\frac{1}{2} \gamma_{0_{p}} \operatorname{Var}_{t}\left(\left.\rho_{0_{p} t}\right|_{\mathfrak{M}_{3}}\right)\right\}
$$

$\left.\omega_{10_{p} t}\right|_{\mathfrak{M}_{3}}$ and $\left.\omega_{20_{p} t}\right|_{\mathfrak{M}_{3}}$ denoting the weights (under model structure $\mathfrak{M}_{3}$ ) in the time $t$ portfolio of the private investors in country 0 of the bonds denominated in the currencies of country 1 and country 2, respectively, $\left.\rho_{0_{p}}\right|_{\mathfrak{M}_{3}}$ denoting the real rate of return from $t$ to $t+1$ on the portfolio of the private investors in country 0 (under model structure $\mathfrak{M}_{3}$ ), with

$$
\left.\rho_{0_{p} t}\right|_{\mathfrak{M}_{3}}=\left(1-\left.\omega_{10_{p} t}\right|_{\mathfrak{M}_{3}}-\left.\omega_{20_{p} t}\right|_{\mathfrak{M}_{3}}\right)\left(R_{0 t}-\pi_{0, t+1}\right)+\left.\sum_{i=1}^{2} \omega_{i 0_{p} t}\right|_{\mathfrak{M}_{3}}\left(R_{i t}+\psi_{0 i, t+1}-\pi_{0, t+1}\right)
$$

and with $\psi_{0 i, t+1}$ the rate of appreciation of the currency of country $i$ against the currency of country 0 from $t$ to $t+1$, and

$$
\left.\omega_{i 0_{p} t}\right|_{\mathfrak{M}_{3}}=\frac{Q_{0 i t} B_{i 0_{p} t}}{B_{00_{p} t}+Q_{01 t} B_{10_{p} t}+Q_{02 t} B_{20_{p} t}}, \quad i=1,2,
$$


$Q_{0 i t}$ denoting the time $t$ nominal spot exchange rate between countries 0 and $i$ (measured as units of currency of country 0 per one single unit of currency of country $i$ ). We suppose in analogy to (3.6) and (3.7) that

$$
E_{t}\left(\psi_{0 i, t+1}\right)=\mu_{\psi_{0 i} t}, \quad \operatorname{Var}_{t}\left(\psi_{0 i, t+1}\right)=\sigma_{\psi_{0 i}}^{2}, \quad i=1,2,
$$

and

$$
\operatorname{Cov}_{t}\left(\pi_{0, t+1}, \psi_{0 i, t+1}\right)=\sigma_{\pi_{0}, \psi_{0 i}}, \quad i=1,2, \quad \operatorname{Cov}_{t}\left(\psi_{01, t+1}, \psi_{02, t+1}\right)=\sigma_{\psi_{01}, \psi_{02}}
$$

Solving the optimization problem given by (3.10) to (3.14), it is readily established that the time $t$ optimal portfolio share of the bond denominated in the currency of country 1 by the private investors in country 0 under model structure $\mathfrak{M}_{3}$ is given by

$$
\begin{aligned}
\left.\omega_{10_{p} t}\right|_{\mathfrak{M}_{3}}= & \left(\frac{1}{1-\rho_{\psi_{01}, \psi_{02}}^{2}}\right)\left[\left(\frac{R_{1 t}+\mu_{\psi_{01} t}-R_{0 t}}{\gamma_{0_{p}} \sigma_{\psi_{01}}^{2}}+\frac{\sigma_{\pi_{0}, \psi_{01}}}{\sigma_{\psi_{01}}^{2}}\right)\right. \\
& \left.-\rho_{\psi_{01}, \psi_{02}}^{2}\left(\frac{R_{2 t}+\mu_{\psi_{02} t}-R_{0 t}}{\gamma_{0_{p}} \sigma_{\psi_{01}, \psi_{02}}}+\frac{\sigma_{\pi_{0}, \psi_{02}}}{\sigma_{\psi_{01}, \psi_{02}}}\right)\right],
\end{aligned}
$$

with

$$
\rho_{\psi_{01}, \psi_{02}}^{2}=\frac{\sigma_{\psi_{01}, \psi_{02}}^{2}}{\sigma_{\psi_{01}}^{2} \sigma_{\psi_{02}}^{2}}
$$

From (3.15), the optimal portfolio share of the bond denominated in the currency of country 1 for the private investor in country 0 under model structure $\mathfrak{M}_{3}$ is a function (i) of both the excess rate of return of the bond denominated in the currency of country 1 as well as the excess rate of return of the bond denominated in the currency of country 2, as well as (ii) the hedge both the bond denominated in the currency of country 1 as well as the bond denominated in the currency of country 2 provide against inflation in country 0 . The optimal portfolio share of the bond denominated in the currency of country 1 for the private investors in country 0 under model structure $\mathfrak{M}_{3}$ will generally only be the same as it is in the two-country model, model structure $\mathfrak{M}_{2}$, if

$$
\sigma_{\psi_{01}, \psi_{02}}=0
$$

Such an orthogonality restriction on the dynamics of different exchange rate pairs is, however, extremely unlikely to hold in empirical practice.

Also solving under model structure $\mathfrak{M}_{2}$ the optimization problem of the investors in country 1 , and under model structure $\mathfrak{M}_{3}$ the optimization problems of the investors in countries 2 and 3 , upon substituting the complete set of optimal portfolio shares into the relevant market clearing 
condition, (Equation (3.1) under model structure $\mathfrak{M}_{2}$ and Equation (3.9) under model structure $\mathfrak{M}_{3}$ ), and then differentiating the resultant identities under the implicit function theorem with respect to $Q_{01 t}$ and $R_{0 t}$, it can be shown that ${ }^{9}$

$$
\left.\frac{\partial Q_{01 t}}{\partial R_{0 t}}\right|_{\mathfrak{M}_{2}} \neq\left.\frac{\partial Q_{01 t}}{\partial R_{0 t}}\right|_{\mathfrak{M}_{3}},
$$

unless the orthogonality condition of Equation (3.17) holds, which, again, is extremely unlikely to be the case in empirical practice. Thus, a bilateral analysis of monetary policy changes in country 0 that includes only the variables of countries 0 and 1 will generally be subject to an omitted variables problem. The variables for country 2 generally need to be included as well. Through calibration-style exercises, we have established that under reasonable parameterizations of model structures $\mathfrak{M}_{2}$ and $\mathfrak{M}_{3}$ the instantaneous bilateral and/or effective exchange rate appreciations for the currency of country 0 caused by a contractionary monetary policy shock in country 0 may in the three-country model be either weaker or stronger than in the two-country model. The strength of the exchange rate effects of a monetary policy change thus seems to be primarily an empirical question.

Rather than augmenting our simple stylized model to capture frictions that within the model will lead to exchange rate overshooting, in this paper we restrict ourselves to building and estimating an empirical model heeding the main insight of Equation (3.18): The exchange rate and forward premium effects of monetary policy shocks in the presence of more than two countries will generally be mis-measured in a bilateral (two-country) model. A multilateral model is called for, capturing the complete spectrum of the relevant cross-country exchange rate correlations. ${ }^{10}$

\section{An Empirical Multilateral Model}

\subsection{A Global Vector Error Correction Model (GVECM)}

A common limitation of the empirical models considered in the previous literature on the exchange rate effects of monetary policy is that they omit considering the simultaneous nature of the international spillover effects that a monetary policy shock will cause. To address this problem, we work with a Global VAR (GVAR) model as proposed by Pesaran, Schuermann, and Weiner (2004). Suppose that there are $T$ sample periods, $t=1,2, \ldots, T$, and $N+1$ countries, the countries indexed by $i=0,1,2, \ldots, N$. For each country, we wish to model a vector $\mathbf{x}_{i t}$ of $m$ country-specific

\footnotetext{
${ }^{9}$ The algebraic details are described in a note available from the authors upon request.

${ }^{10}$ We do not address in this paper the question as to the minimum number of countries that is needed to avoid sizeable mis-measurement due to an omitted countries bias. The answer to this question is likely to be sample specific, and in this paper we simply take the approach of working with a panel of major industrial economies spanning Northern America, Europe as well as East Asia and the Pacific.
} 
endogenous variables. Stacking the vectors of country-specific endogenous variables,

$$
\mathbf{x}_{t}=\left(\mathbf{x}_{0 t}^{\prime}, \quad \mathbf{x}_{1 t}^{\prime}, \ldots, \mathbf{x}_{N t}^{\prime}\right)^{\prime}
$$

a VAR model in $\mathbf{x}_{t}$ obviously would contain ways too many parameters to be estimable unless the time dimension, $T$, of each country's data series would by far exceed the cross-sectional dimension, $N+1$. Therefore, rather than letting $\mathbf{x}_{-i, t}$,

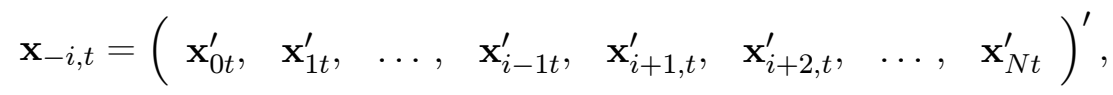

enter the set of equations for country $i$ in unrestricted form, the GVAR model involves a structural cross-country interdependence restriction, namely relating $\mathbf{x}_{i t}$ "only" to an $m^{*} \times 1$ dimensional vector $\mathbf{x}_{i t}^{*}$,

$$
\mathbf{x}_{\ell i t}^{*}=\sum_{j=0}^{N} w_{\ell i j} x_{\ell j t}, \text { with } w_{\ell i j}=0 \text { for } i=j, \ell=1,2, \ldots, m^{*}
$$

and where $\sum_{j=0}^{N} w_{\ell i j}=1$, for all relevant $\ell$ and all $i$, the weights $w_{\ell i j}$ reflecting the economic importance of country $j$ for country $i{ }^{11}$ The GVAR model for country $i$ is then given by

$$
\mathbf{x}_{i t}=\mathbf{a}_{i 0}+\mathbf{a}_{i 1} t+\sum_{s=1}^{p_{i}} \Phi_{i s} \mathbf{x}_{i, t-s}+\sum_{s=0}^{q_{i}} \Lambda_{i s} \mathbf{x}_{i, t-s}^{*}+\sum_{s=0}^{d_{i}} \Upsilon_{i s} \mathbf{d}_{t-s}+\mathbf{u}_{i t}, \quad \mathbf{u}_{i t} \stackrel{i i d(\text { for } t)}{\sim}\left(\mathbf{0}, \Sigma_{\mathbf{u}_{i}}\right),
$$

where $\mathbf{d}_{t}$ is a $q \times 1$ dimensional vector of observed common factors. The vectors of country-specific foreign variables $\mathbf{x}_{i, t-s}^{*}$ account for direct spillovers across countries and may also proxy the influence of unobserved common factors across countries. The weights $w_{\ell i j}$ entering the construction of $\mathbf{x}_{i, t-s}^{*}$ capture the differential effects that different foreign countries have on domestic economy variables, and impose the restriction that the magnitude of the spillovers from a foreign economy onto the domestic economy is in proportion to the weighting scheme. The foreign variables and the observed common factors in $\mathbf{d}_{t}$ in Equation (4.4) are treated as weakly exogenous.

In order to distinguish between temporary and permanent shocks, we re-write Equation (4.4) in error-correction format, rendering the Global Vector Error Correction Model (GVECM):

$$
\Delta \mathbf{x}_{i t}=\mathbf{a}_{i 0}+\mathbf{a}_{i 1} t+\Pi_{i} \mathbf{z}_{i, t-1}+\sum_{s=1}^{p-1} \Psi_{i s} \Delta \mathbf{z}_{i, t-s}+\Gamma_{i} \Delta \widetilde{\mathbf{z}}_{i t}+\mathbf{u}_{i t}
$$

where

$$
\Pi_{i}=\left(-\mathbf{I}_{m}+\sum_{s=1}^{p} \Phi_{i s}, \quad \sum_{s=0}^{p} \Lambda_{i s}, \quad \sum_{s=0}^{p} \Upsilon_{i s}\right), \mathbf{z}_{i t}=\left(\mathbf{x}_{i t}^{\prime}, \mathbf{x}_{i t}^{*^{\prime}}, \mathbf{d}_{t}^{\prime}\right)^{\prime},
$$

\footnotetext{
${ }^{11}$ In this paper, we will use trade weights to construct the $w_{\ell i j}$ 's. To capture a separate financial market channel of cross-country spillovers, one might like to (also) consider financial capital flow based weights, in particular for financial market variables. As the necessary broad set of bilateral data on financial capital flow based weights at present are not available, we restrict ourselves to trade weights in this paper.
} 


$$
\begin{aligned}
& p=\max _{i}\left\{p_{i}, q_{i}, d_{i}\right\}, \Psi_{i s}=\left(-\sum_{q=s+1}^{p} \Phi_{i s}, \quad-\sum_{q=s+1}^{p} \Lambda_{i s}, \quad-\sum_{q=s+1}^{p} \Upsilon_{i s}\right), \\
& \widetilde{\mathbf{z}}_{i t}=\left(\mathbf{x}_{i t}^{*^{\prime}}, \mathbf{d}_{t}^{\prime}\right)^{\prime}, \text { and } \Gamma_{i}=\left(\begin{array}{cc}
\Lambda_{i 0}, & \Upsilon_{i 0}
\end{array}\right)
\end{aligned}
$$

The matrix $\Pi_{i}$ may be decomposed as $\Pi_{i}=\boldsymbol{\alpha}_{i} \boldsymbol{\beta}_{i}^{\prime}$, where $\boldsymbol{\beta}_{i}$ is the matrix of cointegrating relations.

It would be an enormous task to simultaneously estimate a system in $\Delta \mathbf{x}_{t}$, with each $\Delta \mathbf{x}_{i t}$ generated by Equation (4.5). The GVECM can, however, be readily estimated on a country-by country basis if the degree of cross-country dependence of the idiosyncratic shocks, $\mathbf{u}_{i t}$, is sufficiently small, so that

$$
\sum_{j=0}^{N} \frac{\operatorname{Cov}\left(u_{\ell i t}, u_{m j t}\right)}{N} \rightarrow 0 \text { as } N \rightarrow \infty, \text { for all } i \neq j, \ell \text { and } m .
$$

The condition in Equation (4.9), established by Pesaran, Schuermann, and Weiner (2004), may be viewed as weakening one of Zellner's (1962) conditions under which a seemingly unrelated equation system can be estimated on an equation-by-equation basis, namely if the variance-covariance matrix of the system is diagonal. The condition in Equation (4.9) requires that the cross-country interdependencies asymptotically are captured through the foreign variables and the observed common factors in $\mathbf{d}_{t} \cdot{ }^{12}$

Upon country-by-country estimation of the GVECM - which can be accomplished using the methodology of Pesaran, Shin, and Smith (2000) - for an impulse reponse analysis it is necessary to obtain the implied global solution for $\mathbf{x}_{t} \cdot{ }^{13}$ To obtain the global solution in levels form, note that Equation (4.4) can also be re-written as

$$
\mathbf{A}_{i} \mathbf{y}_{i t}=\mathbf{a}_{i 0}+\mathbf{a}_{i 1} t+\sum_{s=1}^{p} \mathbf{B}_{i s} \mathbf{y}_{i, t-s}+\sum_{s=0}^{d_{i}} \Upsilon_{i s} \mathbf{d}_{t-s}+\mathbf{u}_{i t}
$$

where

$$
\mathbf{y}_{i t}=\left(\mathbf{x}_{i t}^{\prime}, \mathbf{x}_{i t}^{*^{\prime}}\right)^{\prime}, \mathbf{A}_{i}=\left(\mathbf{I}_{m},-\Lambda_{i 0}\right), \text { and } \mathbf{B}_{i s}=\left(\begin{array}{cc}
\Phi_{i s}, & \Lambda_{i s}
\end{array}\right) .
$$

From Equation (4.3), it is readily seen that

$$
\mathbf{y}_{i t}=\mathbf{W}_{i} \mathbf{x}_{t}
$$

\footnotetext{
${ }^{12}$ If the foreign variables and the observed common factors in $\mathbf{d}_{t}$ in Equation (4.4) cannot be treated as weakly exogenous, the GVECM can still be estimated on a country-by-country basis, but the equation system for country $i$ then will need to include the equations in $\mathbf{x}_{i t}^{*^{\prime}}$ and $\mathbf{d}_{t}^{\prime}$.

${ }^{13}$ Impulse reponse analysis cannot be carried out on the basis of the GVECM representation in Equation (4.5), as any innovation in $\mathbf{u}_{i t}$ in general causes responses of all elements of $\mathbf{x}_{t}$, and thus the foreign variables entering Equation (4.5) cannot be modelled as being unaffected by innovations in $\mathbf{u}_{i t}$.
} 
for an appropriately defined weighting and selection matrix $\mathbf{W}_{i}$. By stacking Equation (4.10) across all $i$, the resultant multilateral ("global") model can be re-written as

$$
\mathbf{G} \mathbf{x}_{t}=\mathbf{a}_{0}+\mathbf{a}_{1} t+\sum_{s=1}^{p} \mathbf{H}_{s} \mathbf{x}_{t-s}+\sum_{s=0}^{p} \Upsilon_{s} \mathbf{d}_{t-s}+\mathbf{u}_{t}
$$

where

$$
\begin{gathered}
\mathbf{G}=\left(\begin{array}{c}
\mathbf{A}_{0} \mathbf{W}_{0} \\
\mathbf{A}_{1} \mathbf{W}_{1} \\
\vdots \\
\mathbf{A}_{N} \mathbf{W}_{N}
\end{array}\right), \mathbf{a}_{0}=\left(\begin{array}{c}
\mathbf{a}_{00} \\
\mathbf{a}_{10} \\
\vdots \\
\mathbf{a}_{N 0}
\end{array}\right), \mathbf{a}_{1}=\left(\begin{array}{c}
\mathbf{a}_{01} \\
\mathbf{a}_{11} \\
\vdots \\
\mathbf{a}_{N 1}
\end{array}\right), \\
\mathbf{H}_{s}=\left(\begin{array}{c}
\mathbf{B}_{0 s} \mathbf{W}_{0} \\
\mathbf{B}_{1 s} \mathbf{W}_{1} \\
\vdots \\
\mathbf{B}_{N s} \mathbf{W}_{N}
\end{array}\right), \Upsilon_{s}=\left(\begin{array}{c}
\Upsilon_{0 s} \\
\Upsilon_{1 s} \\
\vdots \\
\Upsilon_{N s}
\end{array}\right), \text { and } \mathbf{u}_{t}=\left(\begin{array}{c}
\mathbf{u}_{0 t} \\
\mathbf{u}_{1 t} \\
\vdots \\
\mathbf{u}_{N t}
\end{array}\right) .
\end{gathered}
$$

The matrix $\mathbf{G}$ can in general be expected to be of full rank, in which case the global solution in levels form is given by

$$
\mathbf{x}_{t}=\mathbf{G}^{-1} \mathbf{a}_{0}+\mathbf{G}^{-1} \mathbf{a}_{1} t+\sum_{s=1}^{p} \mathbf{G}^{-1} \mathbf{H}_{s} \mathbf{x}_{t-s}+\sum_{s=0}^{p} \Upsilon_{s} \mathbf{d}_{t-s}+\mathbf{G}^{-1} \mathbf{u}_{t} .
$$

The global solution in Equation (4.16) indeed is a VAR for the union of all countries' sets of domestic variables. The key feature of the GVAR/GVECM framework is that it allows to estimate Equation (4.16) indirectly on a country-by-country basis, allowing for the consideration of a larger number of countries and richer country-specific model formulations than would ever be feasible if it was attempted to estimate Equation (4.16) directly.

\subsection{GVECM Variables and Data}

We consider the sample period from January 1978 to December 2006 for nine industrial countries: Australia, Canada, France, Germany, Italy, Japan, New Zealand, the United Kingdom, and the United States. The vector of domestic variables for each country is given by:

$$
\mathbf{x}_{i t}=\left(\begin{array}{lllll}
y_{i t} & P_{i t} & R_{i t}^{m} & R_{i t} & Q_{i t}
\end{array}\right)^{\prime}
$$

where (in all cases for country $i$ at time $t$ ) $y_{i t}$ denotes the logarithm of real industrial production, $P_{i t}$ the logarithm of the consumer price index, $R_{i t}^{m}$ the monetary policy indicator (in fractions), $R_{i t}$ the short-term nominal interest rate (typically a three-months treasury-bill type rate, in fractions), 
and $Q_{i t}$ the effective nominal exchange rate. The corresponding country-specific foreign variables are given by:

$$
\mathbf{x}_{i t}^{*}=\left(\begin{array}{llll}
y_{i t}^{*} & P_{i t}^{*} & R_{i t}^{*} & Q_{i t}^{*}
\end{array}\right)^{\prime},
$$

each foreign variable defined as in Equation (4.3). Note that we do not construct country-specific foreign variables for the monetary policy indicator, since for each country the indicator reflects different variables (we will discuss our choice of the monetary policy indicators in Section 5). Following most of the GVAR literature, the weights we use for the construction of the foreign variables and the effective exchange rates are average trade weights based on a middle period in the sample (namely, from January 1991 to December 1993).

The observed common factor $\mathbf{d}_{t}$ we specify to be the logarithm of spot world market oil prices and of a commodity price index for agricultural raw materials.

While it would, of course, be of interest to use a real-time database for our empirical analysis, due to lack of the required real-time databases for the majority of the countries in our sample, our data incorporates all data revisions that have been made to date since initial release of the data. This is consistent with all of the previous empirical papers on the exchange rate effects of monetary policy shocks as cited in the Introduction and in Section 2. It should also be noted that the findings of Croushore and Evans (2006) suggest that key results regarding the effects of U.S. monetary policy shocks are the same when real-time data sets are used as when data sets incorporating data revisions are used.

\section{$5 \quad$ Measuring Monetary Policy Shocks}

\subsection{Monetary Policy Indicators}

Let us turn to the issue of measuring the monetary policy shock. First, we need to choose the indicators that for each country seem to best measure the monetary policy stance. It has been widely recognized in the literature that monetary aggregates do not represent satisfactory measures of the monetary policy stance, as changes of monetary aggregates involve various non-policy influences and reflect both changes of money demand and money supply. ${ }^{14}$ Hence we focus on other variables such as short-term interest rates and reserve ratios. Let us briefly discuss our choices for each country.

For the United States, we consider two alternatives: the federal funds rate $(F F R)$ and the ratio between non-borrowed reserves and total reserves (nbrx). The FFR has been the Federal Reserve's operating target for most of our sample period; announcing the federal funds target rate has been a major policy signal channel for the Federal Reserve. Thus we believe that the FFR closely reflects

\footnotetext{
${ }^{14}$ See, for example, Bernanke and Mihov (1998).
} 
the Federal Reserve's policy stance. This is also supported by empirical evidence. Bernanke and Mihov (1998), for example, conclude that it seems best to measure the Federal Reserve's monetary policy stance using the FFR prior to 1979 and nbrx from 1979 to 1982, and either FFR or nbrx for more recent periods. Therefore, we choose the $F F R$ for our default analysis, and augment our analysis with nbrx for robustness checks.

For Canada, it appears that the Bank of Canada's overnight rate contains much of the relevant information about the Bank of Canada's monetary policy stance. The Bank of Canada announces the target rate for the overnight rate to send policy signals (Armour, Engert, and Fung, 1996). According to the analysis of Armour, Engert, and Fung (1996), the path of the overnight rate is consistent with the policy record of the Bank of Canada from the 1970s, and is preferable compared to use of other alternatives such as the 90-days paper rate term spread (the 90-days paper rate minus the yield on ten-years or longer maturity Canadian government bonds). Therefore, we choose the overnight rate as the indicator of Canadian monetary policy.

For the European countries France, Germany, and Italy, as first candidates for measures of the monetary policy stance we consider money market rates as the target rates steered by their respective central banks. Before 1999, unlike the Federal Reserve and the Bank of Canada that sent signals mainly through announcements of target rates, these European countries' central banks used various strategies to signal their monetary policy stance, including tender rates in open market operations, quantity signals, and standing facilities. The Bank of France used repurchases of government and private claims as its major operation; important signals were sent via various repurchase rates. Even among the tender rates, no single rate seems to have adequately captured the complete monetary policy stance of the Bank of France, though. The Deutsche Bundesbank's lombard rate, constituting an upper bound for German money market rates, was an important signal for German monetary policy for many years. The lombard rate and the overnight call rate are identified as useful measures of the Bundesbank's monetary policy stance in Bernanke and Mihov (1997) using data before 1990. From the 1990s on, standing facilities have accounted for less and less of the re-financing, and the day-to-day call money market rate seems to be a more appropriate measure of the Deutsche Bundesbank's monetary policy stance (Brueggemann, 2003). For Italy, in addition to the repurchase rates, the discount window has been conveying the longterm monetary policy stance of the Bank of Italy. De Arcangelis and Di Giorgio (1999) argue that the repurchase agreement rate and the overnight rate have been strong substitutes, and that the Bank of Italy has been targeting the overnight interbank loan rate. Given these considerations, instead of using for France, Germany, and Italy variables that likely reflect only a limited amount of information about monetary policy operations, we prefer to use for the time period prior to the establishment of the European Central Bank country-specific overnight money market rates. For the time period following the introduction of a common monetary policy for the Euro area in 
January 1999, we use the European Overnight Index Average (EONIA) as the monetary policy indicator for France, Germany, and Italy, as the European Central Bank appears to have a strong interest in steering it.

For the United Kingdom, our choice is the "official bank rate". The "official bank rate" includes all the rates that the Bank of England has sequentially used since $1978 .{ }^{15}$

For Japan, we consider the overnight call rate as our primary candidate for the monetary policy indicator for the Bank of Japan, as it was the operating target before 2001 and then again after 2006. Between 2001 and 2006, the Bank of Japan primarily targeted the quantity of bank reserves (for example, McCallum, 2003). Using the overnight call rate as the monetary policy indicator, Miyao (2002) finds plausible effects for apparent changes in the Bank of Japan's monetary policy stance.

For Australia, we use the official cash rate; the target for the official cash rate appears to be a reasonable measure of the Reserve Bank of Australia's monetary policy intentions. ${ }^{16}$ The Reserve Bank of New Zealand targeted settlement cash balances until 1999, and there were no officially set or targeted interest rates during that time period. In March 1999, the official cash rate was introduced to help meet the inflation target. ${ }^{17}$ We therefore use a combination of the discount rate prior to 1999 and the official cash rate thereafter as our monetary policy indicator for the Reserve Bank of New Zealand.

\subsection{Identification of Monetary Policy Shocks in the Global Vector Error Cor- rection Model}

The structural form of the Global Vector Error Correction Model (GVECM) for country $i$ from Equation (4.5) can be represented as

$$
\begin{aligned}
\mathbf{A}_{\mathbf{x} \mathbf{x}, i} \Delta \mathbf{x}_{i t}= & \mathbf{A}_{\mathbf{x x}, i} \mathbf{a}_{i 0}+\mathbf{A}_{\mathbf{x} \mathbf{x}, i} \mathbf{a}_{i 1} t+\mathbf{A}_{\mathbf{x} \mathbf{x}, i} \Pi_{i} \mathbf{z}_{i, t-1}+\mathbf{A}_{\mathbf{x x}, i} \sum_{s=1}^{p-1} \Psi_{i s} \Delta \mathbf{z}_{i, t-s} \\
& +\mathbf{A}_{\mathbf{x x}, i} \Gamma_{i} \Delta \widetilde{\mathbf{z}}_{i t}+\varepsilon_{\mathbf{x} i t}, \quad \varepsilon_{\mathbf{x} i t} \stackrel{i i d .(\text { for } t)}{\sim}\left(\mathbf{0}, \Sigma_{\boldsymbol{\varepsilon}_{\mathbf{x} i}}\right)
\end{aligned}
$$

with the reduced form shocks in $\mathbf{u}_{i t}$ are related to the structural shocks in $\varepsilon_{\mathbf{x} i t}$ as $\mathbf{u}_{i t}=\mathbf{A}_{\mathbf{x x}, i}^{-1} \varepsilon_{\mathbf{x} i t}$. Let us suppose that the processes for the foreign variables in $\mathbf{x}_{i t}^{*}$ and the common factors in $\mathbf{d}_{t}$ are given by

$$
\Delta \widetilde{\mathbf{z}}_{i t}=\mathbf{b}_{i 0}+\sum_{s=1}^{p-1} \Theta_{i s} \Delta \widetilde{\mathbf{z}}_{i, t-s}+\boldsymbol{\varepsilon}_{\widetilde{\mathbf{z}} i t}, \quad \boldsymbol{\varepsilon}_{\widetilde{\mathbf{z}} i t}^{i . i . d .(\text { for } t)}\left(\mathbf{0}, \Sigma_{\boldsymbol{\varepsilon}_{\widetilde{\mathbf{z}} i}}\right) .
$$

\footnotetext{
${ }^{15}$ The precise measurement of the official bank rate has changed several times. For further details, see http://www.bankofengland.co.uk/mfsd/iadb/notesiadb/Wholesale_discount.htm\#BANK\%20RATE

${ }^{16}$ http://www.rba.gov.au/MonetaryPolicy/about_monetary_policy.html

${ }^{17}$ http://www.rbnz.govt.nz/monpol/about/0047041.html
} 
with, as before, $\widetilde{\mathbf{z}}_{i t}=\left(\begin{array}{ll}\mathbf{x}_{i t}^{* \prime} & \mathbf{d}_{t}^{\prime}\end{array}\right)^{\prime}$. We need to identify the $m^{2}$ elements in $\mathbf{A}_{\mathbf{x x}, i}$. As is standard in the literature, we normalize $E\left(\varepsilon_{\mathbf{x} i t} \varepsilon_{\mathbf{x} i t}^{\prime}\right)=\mathbf{I}_{m}$, that is $E\left(\mathbf{A}_{\mathbf{x x}, i} \mathbf{u}_{i t} \mathbf{u}_{i t}^{\prime} \mathbf{A}_{\mathbf{x x}, i}^{\prime}\right)=\mathbf{I}_{m}$, implying that $\sum_{\mathbf{u}_{i}}=\mathbf{A}_{\mathbf{x x}, i}^{-1} \mathbf{A}_{\mathbf{x x}, i}^{-1 \prime}$. This orthogonality condition provides $m(m+1) / 2$ restrictions for identification. We thus still need an additional $m(m-1) / 2$ restrictions to just-identify $\mathbf{A}_{0, \mathbf{x x}, i}$.

Typical restrictions considered in the VAR literature are to impose $m(m-1) / 2$ short-run (contemporaneous) restrictions, such as by restricting the $\mathbf{A}_{\mathbf{x x}, i}$ matrix to be lower triangular, as in Eichenbaum and Evans (1995). In this case, a strong causal ordering assumption for the model variables is made, rendering the contemporaneous variable interaction structure recursive. Such a recursive structure from the perspective of macroeconomic theory.seems unlikely to hold. Impulse responses from such a recursive structure based identification scheme, known as orthogonalized impulse reponses, also often are sensitive to the ordering of the variables.

In our GVECM, the cointegrating relationships provide us with useful information for the identification of the structural shocks, enabling us to work with identifying assumptions that from the perspective of macroeconomic theory are considerably weaker than those underlying orthogonalized impulse reponses. ${ }^{18}$ We stack Equations (5.1) and (5.2) to obtain

$$
\mathbf{A}_{i} \Delta \mathbf{z}_{i t}=\mathbf{c}_{i 0}+\mathbf{c}_{i 1} t+\widetilde{\Pi}_{i} \mathbf{z}_{i, t-1}+\sum_{s=1}^{p-1} \Xi_{i s} \Delta \mathbf{z}_{i, t-s}+\varepsilon_{i t}
$$

where

$$
\begin{gathered}
\mathbf{A}_{i}=\left(\begin{array}{cc}
\mathbf{A}_{\mathbf{x x}, i} & -\mathbf{A}_{\mathbf{x x}, i} \Gamma_{i} \\
\mathbf{0}_{\left(m^{*}+q\right) \times m} & \mathbf{I}_{m^{*}+q}
\end{array}\right), \mathbf{c}_{i 0}=\left(\begin{array}{c}
\mathbf{A}_{\mathbf{x x}, i} \mathbf{a}_{i 0} \\
\mathbf{b}_{i 0}
\end{array}\right), \mathbf{c}_{i 1}=\left(\begin{array}{c}
\mathbf{A}_{\mathbf{x x}, i} \mathbf{a}_{i 1} \\
\mathbf{0}_{\left(m^{*}+q\right) \times 1}
\end{array}\right), \\
\widetilde{\Pi}_{i}=\left(\begin{array}{c}
\mathbf{A}_{\mathbf{x x}, i} \Pi_{i} \\
\mathbf{0}_{\left(m^{*}+q\right) \times n}
\end{array}\right), \Xi_{i s}=\left(\begin{array}{c}
\mathbf{A}_{\mathbf{x x}, i} \Psi_{i s} \\
\Theta_{i s}
\end{array}\right), \boldsymbol{\varepsilon}_{i t}=\left(\begin{array}{c}
\boldsymbol{\varepsilon}_{\mathbf{x} i t} \\
\boldsymbol{\varepsilon}_{\widetilde{\mathbf{z}} i t}
\end{array}\right),
\end{gathered}
$$

and $k=m+m^{*}+q$. Suppose that we have $r$ cointegrating relationships among the total of $k$ variables in $\mathbf{z}_{i t}$. We can then represent $\left\{\mathbf{z}_{i t}\right\}$ as

$$
\mathbf{z}_{i t}=\mathbf{z}_{i 0}+\mathbf{C}_{i} \sum_{s=1}^{t} \mathbf{u}_{i s}+\sum_{s=1}^{\infty} \mathbf{C}_{i s}^{*} \mathbf{u}_{i, t-s}
$$

\footnotetext{
${ }^{18}$ Faust and Leeper (1997) in the context of a bivariate VAR argue against a long-run identification scheme with one transitory and one permanent shock, as such a scheme may lead to misidentification when the true empirical model features a larger number of shocks than the estimated model. In line with the arguments in Pagan and Pesaran (2008), we view long-run identifying restrictions not just as weaker than corresponding short-run restrictions from the perspective of macroeconomic theory, but also as recognizing existing properties of a dynamic model with cointegrating relations. Furthermore, there is a wealth of econometric evidence (much of it reviewed, for example, in Luetkepohl, 2007), that for the type of data sample we are working with in this paper, such models can be estimated with a satisfactory degree of reliability.
} 
where $\mathbf{C}_{i}=\boldsymbol{\beta}_{i \perp}\left[\widetilde{\boldsymbol{\alpha}}_{i \perp}^{\prime}\left(\mathbf{I}-\sum_{s=1}^{p-1} \Xi_{i s}\right) \boldsymbol{\beta}_{i \perp}\right]^{-1} \widetilde{\boldsymbol{\alpha}}_{i \perp}^{\prime}$, with $\widetilde{\boldsymbol{\alpha}}_{i \perp}^{\prime} \widetilde{\boldsymbol{\alpha}}_{i}=\mathbf{0}$ and $\boldsymbol{\beta}_{i}^{\prime} \boldsymbol{\beta}_{i \perp}=\mathbf{0}$, so that $\mathbf{C}_{i} \widetilde{\boldsymbol{\alpha}}_{i}=\mathbf{0}_{k \times r}$ and $\boldsymbol{\beta}_{i}^{\prime} \mathbf{C}_{i}=\mathbf{0}_{r \times k} ; \mathbf{z}_{i 0}$ is an initialization of $\left\{\mathbf{z}_{i t}\right\}$. It is well known (for a review, see, for example, Pesaran, Shin, and Smith, 2000) that $\sum_{s=1}^{t} \mathbf{u}_{i s}$ is a vector of random walks, and that $\mathbf{C}_{i s}^{*}$ is absolutely summable, with $\mathbf{C}_{i s}^{*}$ converging to the zero matrix as $s \rightarrow \infty$. Therefore, the long-run effects of innovations to $\mathbf{u}_{i t}$ are fully captured through common trend component $\mathbf{C}_{i} \sum_{s=1}^{t} \mathbf{u}_{i s}$. As $\mathbf{C}_{i}$ has rank $k-r$, there are $k-r$ stochastic trends that are driving the system in $\mathbf{z}_{i t}$. Moving from a representation involving the reduced form disturbances in $\mathbf{u}_{i t}$ to one involving the structural disturbances in $\varepsilon_{i t}$, Equation (5.6) can be re-written as

$$
\mathbf{z}_{i t}=\mathbf{z}_{i 0}+\mathbf{C}_{i} \mathbf{A}_{i}^{-1} \sum_{s=1}^{t} \varepsilon_{i s}+\sum_{s=1}^{\infty} \mathbf{C}_{i s}^{*} \mathbf{A}_{i}^{-1} \varepsilon_{i, t-s}
$$

with

$$
\begin{aligned}
\mathbf{C}_{i} \mathbf{A}_{i}^{-1} & =\left(\begin{array}{ll}
\mathbf{C}_{\mathbf{x x}, i} & \mathbf{C}_{\mathbf{x} \widetilde{\mathbf{z}}, i} \\
\mathbf{C}_{\widetilde{\mathbf{z}} \mathbf{x}, i} & \mathbf{C}_{\widetilde{\mathbf{z}}, i}
\end{array}\right)\left(\begin{array}{cc}
\mathbf{A}_{\mathbf{x x}, i}^{-1} & -\left(\mathbf{A}_{\mathbf{x x}, i} \Gamma_{i}\right)^{-1} \\
\mathbf{0}_{\left(m^{*}+q\right) \times m} & \mathbf{I}_{m^{*}+q}
\end{array}\right) \\
& =\left(\begin{array}{cc}
\mathbf{C}_{\mathbf{x x}, i} \mathbf{A}_{\mathbf{x x}, i}^{-1} & -\mathbf{C}_{\mathbf{x x}, i}\left(\mathbf{A}_{\mathbf{x x}, i} \Gamma_{i}\right)^{-1}+\mathbf{C}_{\mathbf{x} \widetilde{\mathbf{z}}, i} \\
\mathbf{C}_{\widetilde{\mathbf{z}} \mathbf{x}, i} \mathbf{A}_{\mathbf{x x}, i}^{-1} & -\mathbf{C}_{\widetilde{\mathbf{z}} \mathbf{x}, i}\left(\mathbf{A}_{\mathbf{x x}, i} \Gamma_{i}\right)^{-1}+\mathbf{C}_{\widetilde{\mathbf{z}}, i}
\end{array}\right) .
\end{aligned}
$$

Clearly, $\mathbf{A}_{i}$ is non-singular, and thus $\mathbf{C}_{i} \mathbf{A}_{i}^{-1}$ is of rank $k-r$, that is, only $k-r$ structural shocks have long-run effects on the total of $k$ variables in $\mathbf{z}_{i t}$. If the foreign variables in $\mathbf{x}_{i t}^{*}$ and the common factors in $\mathbf{d}_{t}$ are weakly exogenous $I(1)$ processes, and there are no cointegrating relations among these, then the shocks to these variables will be among those having long-run effects.

For most of the empirical analysis of this paper, we will focus on the effects of U.S. monetary policy shocks. For the U.S., we find that there are three cointegrating relations. Let us thus discuss the case of $r=3$ in more detail. It would seem a strong restriction to impose that the structural shocks to industrial production and to prices have no long-run effects. It seems very reasonable, however, to impose that the structural shocks to the monetary policy indicator, to the short-term interest rate, and to the effective nominal exchange rate have no long-run effects. This assumption renders the columns of $\mathbf{C}_{\mathbf{x x}, i} \mathbf{A}_{\mathbf{x x}, i}^{-1}$ that measure the long-run effects of these shocks equal to zero vectors, reflecting that these shocks only have transitory effects. Placing the structural shocks to the monetary policy indicator, the short-term interest rate, and the effective nominal exchange rate last in the disturbance vector $\varepsilon_{\mathbf{x} i t}$, we have:

$$
\mathbf{C}_{\mathbf{x x}, i} \mathbf{A}_{\mathbf{x x}, i}^{-1}=\left(\begin{array}{cccccc} 
& \varepsilon_{y} & \varepsilon_{P} & \varepsilon_{R^{m}} & \varepsilon_{R} & \varepsilon_{Q} \\
y & * & * & 0 & 0 & 0 \\
P & * & * & 0 & 0 & 0 \\
R^{m} & * & * & 0 & 0 & 0 \\
R & * & * & 0 & 0 & 0 \\
Q & * & * & 0 & 0 & 0
\end{array}\right) .
$$


The zeros in the last three columns of $\mathbf{C}_{\mathbf{x x}, i} \mathbf{A}_{\mathbf{x x}, i}^{-1}$ reflect that we have six (in general $r(m-r)$ ) linearly independent long-run restrictions for structural shock identification. Therefore, we now only need four (in general $m(m-1) / 2-r(m-r)$ ) additional restrictions for a just-identified $\mathbf{A}_{\mathbf{x x}, i}$ matrix. As the first additional restriction, we assume that the shocks to consumer prices do not have long-run effects on real industrial production, so that now

$$
\mathbf{C}_{\mathbf{x x}, i} \mathbf{A}_{\mathbf{x x}, i}^{-1}=\left(\begin{array}{cccccc} 
& \varepsilon_{y} & \varepsilon_{P} & \varepsilon_{R^{m}} & \varepsilon_{R} & \varepsilon_{Q} \\
y & * & 0 & 0 & 0 & 0 \\
P & * & * & 0 & 0 & 0 \\
R^{m} & * & * & 0 & 0 & 0 \\
R & * & * & 0 & 0 & 0 \\
Q & * & * & 0 & 0 & 0
\end{array}\right)
$$

Observing the local uniqueness condition when solving for $\mathbf{A}_{\mathbf{x x}, i},{ }^{19}$ we are left with having to impose three short-run restrictions to complete just-identification of $\mathbf{A}_{\mathbf{x x}, i}$. It appears reasonable to impose that (i) real industrial production does not contemporaneously respond to monetary policy indicator and short-term interest rate shocks, and that (ii) consumer prices do not contemporaneously respond to short-term interest rate shocks:

$$
\mathbf{A}_{\mathbf{x x}, i}=\left(\begin{array}{cccccc} 
& \varepsilon_{y} & \varepsilon_{P} & \varepsilon_{R^{m}} & \varepsilon_{R} & \varepsilon_{Q} \\
y & * & * & 0 & 0 & * \\
P & * & * & * & 0 & * \\
R^{m} & * & * & * & * & * \\
R & * & * & * & * & * \\
Q & * & * & * & * & *
\end{array}\right) .
$$

Having identified the U.S. structural monetary policy shock, we can move to the global solution and the impulse response functions. Recalling the global solution given by Equation (4.16), we first stack it in companion form,

$$
\mathbf{X}_{t}=\widetilde{\mathbf{a}}_{0}+\widetilde{\mathbf{a}}_{1} t+\widetilde{\mathbf{H}} \mathbf{X}_{t-1}+\mathbf{D}_{t}+\mathbf{U}_{t}
$$

where

$$
\mathbf{X}_{t}=\left(\begin{array}{c}
\mathbf{x}_{t} \\
\mathbf{x}_{t-1} \\
\mathbf{x}_{t-2} \\
\vdots \\
\mathbf{x}_{t-p+1}
\end{array}\right), \widetilde{\mathbf{a}}_{0}=\left(\begin{array}{c}
\mathbf{G}^{-1} \mathbf{a}_{0} \\
\mathbf{0}_{(N+1) m \times 1} \\
\mathbf{0}_{(N+1) m \times 1} \\
\vdots \\
\mathbf{0}_{(N+1) m \times 1}
\end{array}\right), \widetilde{\mathbf{a}}_{1}=\left(\begin{array}{c}
\mathbf{G}^{-1} \mathbf{a}_{1} \\
\mathbf{0}_{(N+1) m \times 1} \\
\mathbf{0}_{(N+1) m \times 1} \\
\vdots \\
\mathbf{0}_{(N+1) m \times 1}
\end{array}\right)
$$

\footnotetext{
${ }^{19}$ See, for example, Luetkepohl (2007) for a discussion of the local uniqueness condition.
} 


$$
\widetilde{\mathbf{H}}=\left(\begin{array}{ccccc}
\mathbf{G}^{-1} \mathbf{H}_{1} & \mathbf{G}^{-1} \mathbf{H}_{2} & \cdots & \mathbf{G}^{-1} \mathbf{H}_{p-1} & \mathbf{G}^{-1} \mathbf{H}_{p} \\
\mathbf{I}_{(N+1) m} & \mathbf{0}_{(N+1) m} & \cdots & \mathbf{0}_{(N+1) m} & \mathbf{0}_{(N+1) m} \\
\mathbf{0}_{(N+1) m} & \mathbf{I}_{(N+1) m} & \cdots & \mathbf{0}_{(N+1) m} & \mathbf{0}_{(N+1) m} \\
\vdots & \vdots & \ddots & & \vdots \\
\mathbf{0}_{(N+1) m} & \mathbf{0}_{(N+1) m} & \cdots & \mathbf{I}_{(N+1) m} & \mathbf{0}_{(N+1) m}
\end{array}\right), \mathbf{D}_{t}=\left(\begin{array}{c}
\mathbf{G}^{-1} \sum_{s=0}^{r} \Upsilon_{s} \mathbf{d}_{t-s} \\
\mathbf{0}_{(N+1) m \times 1} \\
\mathbf{0}_{(N+1) m \times 1} \\
\vdots \\
\mathbf{0}_{(N+1) m \times 1}
\end{array}\right)
$$

and

$$
\mathbf{U}_{t}=\left(\begin{array}{c}
\mathbf{G}^{-1} \mathbf{A}_{0} \boldsymbol{\varepsilon}_{t} \\
\mathbf{0}_{(N+1) m \times 1} \\
\mathbf{0}_{(N+1) m \times 1} \\
\vdots \\
\mathbf{0}_{(N+1) m \times 1}
\end{array}\right)
$$

where we take the shock vector $\varepsilon_{t}$ to be composed of the U.S. structural shocks and reduced form shocks for all other countries:

$$
\varepsilon_{t}=\left(\begin{array}{lllll}
\varepsilon_{U S A, t}^{\prime}, & \mathbf{u}_{1 t}^{\prime}, & \mathbf{u}_{2 t}^{\prime}, & \ldots, & \mathbf{u}_{N t}^{\prime}
\end{array}\right)^{\prime},
$$

and

$$
\mathbf{A}_{0}=\left(\begin{array}{ccccc}
\mathbf{A}_{\mathbf{x x}, i}^{-1} & \mathbf{0}_{m} & \mathbf{0}_{m} & \cdots & \mathbf{0}_{m} \\
\mathbf{0}_{m} & \mathbf{I}_{m} & \mathbf{0}_{m} & \cdots & \mathbf{0}_{m} \\
\mathbf{0}_{m} & \mathbf{0}_{m} & \mathbf{I}_{m} & \ddots & \mathbf{0}_{m} \\
\vdots & \vdots & \vdots & & \vdots \\
\mathbf{0}_{m} & \mathbf{0}_{m} & \mathbf{0}_{m} & \cdots & \mathbf{I}_{m}
\end{array}\right)
$$

We should note that identifying the complete set of structural shocks across all countries would result in us having to impose more than 2,000 parameter restrictions on the global solution. We therefore choose to restrict structural identification to the U.S. component of the GVECM, including in particular the U.S. monetary policy shock. Doing so, we actually can also allow for the U.S. structural monetary policy shock to be correlated with any of the reduced form shocks in any of the other countries, and do not need to impose zero contemporaneous impact restrictions for any of the U.S. structural shocks on other countries' variables. On this count, we let the data speak freely. ${ }^{20}$ The $s$-period ahead global impulse response for a U.S. structural monetary policy shock can now be computed as

$$
I R\left(\mathbf{X}_{t+s}\right)=\widetilde{\mathbf{H}}^{s} E\left(\mathbf{U}_{t} \mid \varepsilon_{R_{U S A, t}^{m}}=\kappa\right),
$$

\footnotetext{
${ }^{20}$ In Section 7, we will nevertheless also document the robustness of our main empirical findings to imposing orthogonality on the monetary policy shocks across all countries.
} 
where

$$
E\left(\mathbf{U}_{t} \mid \varepsilon_{R_{U S A, t}^{m}}=\kappa\right)=\left(\begin{array}{c}
\mathbf{G}^{-1} \mathbf{A}_{0} \frac{\operatorname{Var}\left(\boldsymbol{\varepsilon}_{t}\right) \mathbf{e}_{i}}{\operatorname{Var}\left(\boldsymbol{\varepsilon}_{R_{U S}^{m}}^{m}, t\right.} \kappa \\
\mathbf{0}_{(N+1) m \times 1} \\
\mathbf{0}_{(N+1) m \times 1} \\
\vdots \\
\mathbf{0}_{(N+1) m \times 1}
\end{array}\right)
$$

with $\mathbf{e}_{i}$ being the selection vector detailing the location of the U.S. monetary policy shock in the vector $\varepsilon_{t}$.

\section{Empirical Results}

We consider the effects of a contractionary U.S. monetary policy shock, defined in this Section as a one-standard deviation positive innovation of the federal funds rate, and identified as discussed in Section 5. All results in this Section are based on allowing for three cointegrating relations among the domestic and foreign variables for the United States block of the GVECM, as is empirically supported by unit root and cointegration rank tests. ${ }^{21}$

A one-standard deviation positive shock to the federal funds rate represents an almost immediate increase of the federal funds rate of about 30 basis points, before the federal funds rate falls gradually back to its steady state level within about two years (see Figure 3). The other countries' monetary policy indicators do barely respond to the U.S. shock, except for Canada, which features a positive increase in the overnight rate for the first 18 months. This is in contrast to previous empirical studies using bilateral settings, which have found positive and significant responses for foreign countries' monetary policy indicators in response to U.S. monetary policy shocks.

The effects for a consistent cross-country measure of short-term interest rates, three-month bond returns, are by and large similar to those for the monetary policy indicator, with the exception of Canada: The response of Canadian short-term interest rates to a U.S. monetary policy shock is insignificant. Therefore, the U.S. monetary policy shock for the majority of countries in our panel leads to a significant and relatively persistent increase in the spread between U.S. and foreign interest rates. (Figure 4.)

Turning to the nominal and real effective exchange rates, we find that the contractionary U.S. monetary policy shock leads to immediate overshooting of the U.S. Dollar nominal and real effective exchange rates (Figures 5 and 6). Namely, the peak of the exchange rate appreciation occurs in the second month after the federal funds rate shock, before the U.S. Dollar gradually depreciates back to its long-run PPP level within about two and half years. This is in line with standard overshooting

\footnotetext{
${ }^{21}$ The unit root and cointegration test results (as well as test results for weak exogeneity) are documented in an appendix available from the authors upon request.
} 
theory and in contrast to most of the previous empirical findings. There is no delayed overshooting puzzle for the U.S. Dollar effective exchange rate after a domestic contractionary monetary policy shock. The appreciation at the peak is about 0.9 percent for both the nominal and real U.S. Dollar effective exchange rates. The majority of the other countries' nominal effective exchange rates respond to the contractionary U.S. monetary policy shock with a small, often insignificant depreciation (the depreciation is statistically significant for the Canadian Dollar for about six months, the Japanese Yen for about 18 months, and for the Pound Sterling for about three months. The real effective exchange rates behave very similar to the nominal ones.

With regards to the forward premium's response to a contractionary U.S. monetary policy shock, Figure 7 provides these impulse responses. For the U.S. forward premium, except for the first two months, we do not observe a significant conditional short-run deviation from uncovered interest parity. Our finding that there is no significant conditional deviation from uncovered interest parity again is in contrast to most of the previous empirical work. For the other countries in our panel, these do not feature persistently significant short-run forward premia either. Only for the first three to six months there are small but significant forward premia (of the opposite sign as for the United States) for France, Germany, Italy, and Japan.

Figure 8 graphs the impulse responses for the consumer price indices. After a contractionary U.S. monetary policy shock, the consumer price index in the U.S. responds with an increase of about 0.025 percent, which is followed by a gradual fall, until it reaches the long-run response of about -0.1 percent. Only the long-run response is significant. For the other countries, we do not find significant short-run increases of the consumer price indices, though over longer horizons the impulse responses for these price indices fall as well, typically by rather small magnitudes.

Figure 9 summarizes the main findings conveyed by the impulse responses presented so far: For our GVECM, unlike the Eichenbaum and Evans (1995) results as an example of the typical previous empirical findings, there is no delayed exchange rate overshooting puzzle (but rather an almost immediate peak appreciation in response to a U.S. contractionary monetary policy shock that is in line with sticky price macroeconomic models), and there is (except for the first two months after the shock) no significant conditional deviation from uncovered interest parity, again consistent with sticky price macroeconomic models.

It is important to note that our findings of exchange rate and forward premium adjustment paths consistent with conditional uncovered interest parity and a long-run return to purchasing power parity equilibrium in response to a contractionary U.S. monetary policy shock are not implied by findings in favor of uncovered interest parity and/or purchasing power parity as unconditional long-run relationships. Table 1 provides the three U.S. cointegration relations. Table 2 provides tests for uncovered interest parity and purchasing power parity as long-run relationships within our GVECM. Note that the joint validity of the uncovered interest parity and purchasing power 
parity hypotheses is rejected for all nine countries in our sample, and that uncovered interest parity and purchasing power parity individually also are rejected for almost all countries. It is therefore critical to distinguish between different sources of shocks, a finding that again is consistent with the predicitions of the new open economy macroeconomics literature, for example Bergin (2006).

While for space reasons we do not document so in elaborate detail, these results are robust to considerations such as modification of our lag length selection criteria (our default results are based on Schwarz Bayesian Criterion based lag orders) as well as the addition of dummy variables to account for the monetary policy change for some of the European countries in 1999, and to account for German re-unification in 1990. The results are furthermore robust to using a broader commodity price index (rather than spot oil prices) as a common factor in the GVECM.

Finally, as can be seen from Figure 10, the GVAR/GVECM based results indicate that in response to a contractionary monetary policy shock in the countries other than the United States, ${ }^{22}$ in virtually all cases either the bilateral and effective real U.S. Dollar exchange rates either depreciate significantly for a period of between three and 18 months (Canada, Germany, New Zealand, and the United Kingdom), or exhibit no significant reaction.

\section{Model Comparisons and Counterfactual Analysis}

Clearly, the Eichenbaum and Evans (1995) specification and our GVECM specification differ beyond considering bilateral (two-country) versus multilateral (multi-country) settings in several other aspects also:

(i) data sets: relative to Eichenbaum and Evans (1995), we have an extended data set available;

(ii) variable specification: our GVECM includes a larger number of foreign variables than accounted for by Eichenbaum and Evans (1995);

(iii) cointegrating relations: Eichenbaum and Evans (1995) use a level VAR, while our GVECM imposes restrictions implied by empirically supported cointegrating relations;

(iv) monetary policy shock identification: our GVECM exploits a combination of long- and shortrun restrictions for identification purposes, whereas Eichenbaum and Evans (1995) identify monetary policy shocks based on short-run restrictions imposing a recursive ordering of the model variables (the Cholesky decomposition).

Therefore, in order to explore the reasons underlying the remarkable differences between our empirical findings of Section 6 and those of Eichenbaum and Evans (1995), we conduct a step-bystep "counterfactual analysis".

In the first step of this counterfactual analysis, we use our sample from January 1978 to December 2006 to replicate Eichenbaum and Evans (1995), namely, we estimate a bilateral VAR

\footnotetext{
${ }^{22}$ A note describing our identification procedure for monetary policy shocks in countries for which the number of cointegrating relations is, unlike for the U.S., not equal to three, is available from the authors upon request.
} 
for the U.S. versus Germany, containing seven variables, $\left(\begin{array}{ccccccc}y_{t} & P_{t} & y_{t}^{*} & R_{t}^{*} & F F R_{t} & n b r x_{t} & q_{t}\end{array}\right)$, where $y_{t}$ denotes U.S. real industrial production, $P_{t}$ the U.S. consumer price index, $y_{t}^{*}$ German real industrial production, $R_{t}^{*}$ German short-term interest rates, $F F R_{t}$ the federal funds rate as the U.S. monetary policy indicator, $n b r x_{t}$ the ratio between U.S. non-borrowed reserves and U.S. total reserves, and $q_{t}$ the bilateral real exchange rate between the U.S. Dollar and the Deutsche Mark. The lag order is chosen to be six in order to be consistent with Eichenbaum and Evans (1995). The U.S. monetary policy shock is identified using the Cholesky decomposition of the variables (ordered as above), which implies that the Federal Reserve sets the federal funds rate taking into account the lagged values of all variables as well as the current value of U.S. industrial production, the U.S. consumer prices, German industrial production, and German short-term interest rates. To facilitate comparison with Eichenbaum and Evans (1995), the U.S. monetary policy shock throughout our counterfactual analysis in this Section is set to 50 basis points, rather than to one standard deviation, as it was for Figures 3 to 8, Figure 9 (iii) and Figure 10. Figure 11a shows that when incorporating more recent data than Eichenbaum and Evans (1995) could, the peak of the real U.S. Dollar/Deutsche Mark exchange rate impulse response occurs about 10 months after the shock, and thus the delay of overshooting is shorter than found by Eichenbaum and Evans (1995). The federal funds rate and German short-term interest rates behave similarly as in Eichenbaum and Evans (1995), and a significant instantaneous deviation of about 0.8 percent from uncovered interest parity is observed, with significance of this conditional uncovered interest parity deviation holding for up to nine months. Overall, therefore, while the results in the extended sample suggest a less pronounced delayed exchange rate overshooting puzzle than in the original Eichenbaum and Evans (1995) sample, both the delayed exchange rate overshooting puzzle and the forward premium puzzle are not addressed by updating of the Eichenbaum and Evans (1995) sample.

Our next step is to investigate how the key empirical results would change if rather than using German variables we used weighted foreign variables for the U.S. (as well as the full sample of data), within the VAR framework of Eichenbaum and Evans (1995). Therefore, we adapt the Eichenbaum and Evans (1995) VAR specification to contain the same domestic and foreign variables as we use in the U.S. portion of our GVAR: We consider a VAR with the endogenous variables vector

$$
\left(\begin{array}{llllllll}
y_{t} & P_{t} & y_{t}^{*} & P_{t}^{*} & F F R_{t} & R_{t} & R_{t}^{*} & Q_{t}^{*}
\end{array}\right) .
$$

(Note that the starred variables now again denote the weighted sums of the corresponding U.S. variables across all eight countries in our panel foreign to the U.S., instead of referring to one specific foreign country (Germany in the previous step of our counterfactual analysis).) Compared to Eichenbaum and Evans (1995), we add the foreign consumer price index and the U.S. short-term interest rate $R_{t}$, replace the real bilateral U.S. Dollar versus Deutsche Mark exchange rate with the nominal effective U.S. Dollar exchange rate $\left(Q_{t}^{*}\right.$ rather than $\left.q_{t}\right)$, and drop the ratio between U.S. non-borrowed reserves and U.S. total reserves, $n b r x_{t}$. We continue to keep the Cholesky 
decomposition based identification scheme of Eichenbaum and Evans (1995), with the variable ordering as noted in Equation (7.1)). While this is not a truly multilateral specification yet, it captures a larger number of foreign variables than the original Eichenbaum and Evans (1995) specification, and may address issues of potentially peculiar results for specific country pairs. Figure $11 \mathrm{~b}$ provides the impulse responses. The nominal and real effective U.S. Dollar exchange rates still display delayed overshooting, with the peak of the appreciation of the U.S. Dollar occurring approximately 24 to 30 months after the federal funds rate shock. The forward premium exhibits an approximately 0.4 percent deviation from uncovered interest parity right after the U.S. monetary policy shock, before the forward premium returns to zero within about 12 months. Augmenting the bilateral VAR of Eichenbaum and Evans (1995) to capture all variables entering the United States component of our GVECM thus still resolves neither the delayed exchange rate overshooting puzzle nor the forward premium puzzle.

The third step of our counterfactual analysis is to move from the VAR setting to the truly multilateral GVAR setting, specifying separate models for all nine countries in our panel. For each country we consider the five domestic variables $\left(\begin{array}{lllll}y_{i t} & P_{i t} & R_{i t}^{m} & R_{i t} & Q_{i t}\end{array}\right)$, and the four weighted foreign variables $\left(\begin{array}{cccc}y_{i t}^{*} & P_{i t}^{*} & R_{i t}^{*} & Q_{i t}^{*}\end{array}\right)$. The U.S. monetary policy shock is identified in the United States portion of the GVAR using a Wold ordering, and is then incorporated into the global solution. In this analysis, only the order of the domestic variables matters, and we order these as $y_{i t}, P_{i t}, R_{i t}^{m}, R_{i t}$, and $Q_{i t}$. A major difference in empirical results that we obtain for the Cholesky decomposition-based GVAR as compared to the models considered in the first two steps of our counterfactual analysis is that after a U.S. monetary policy shock, the German short-term interest rate displays no significant response (see Figure 11c). The non-GVAR setting appears to overstate the response of German interest rates to U.S. monetary policy shocks. In addition, the federal funds rate falls back to its original levels within 14 months, a shorter adjustment phase than in the bilateral models. The peak responses of the U.S. Dollar nominal and real effective exchange rates occur in the second month after the U.S. monetary policy shock, but except for the first two months these responses are insignificant, and for all months of very small magnitude. The contemporaneous effective forward premium's response is about -0.3 percent, the deviations from uncovered interest parity now being smaller and less persistent than for the bilateral models, with significant responses occurring only for the first four or so months. Figure 11d reports results for the impulse responses implied by this set-up for bilateral U.S. Dollar versus Deutsche Mark nominal and real exchange rates, as well as bilateral forward premia between the United States and Germany. The peak of the overshooting for the bilateral rates occurs with a significant delay of about 12 months only. The forward premium is significant in favor of U.S. bonds for about nine months. Overall, therefore, working with a multilateral GVAR model without considering long-run cointegration based monetary policy shock identification, there still is evidence for the 
delayed exchange rate overshooting and forward premium puzzles. The lack of significance of the U.S. Dollar nominal and real effective exchange rate impulse responses cast, however, doubt on the set-up of a GVAR with the U.S. monetary policy shock being identified on the basis of a Cholesky decomposition.

In the fourth step of our counterfactual analysis, we capture the long-run cointegrating relations of our GVECM set-up, but still use the Cholesky decomposition based monetary policy shock identification of the previous steps of our counterfactual analysis. The results are displayed in Figures 11e and 11f. As for the GVAR results, the German short-term interest rate does not display a significant reaction to the U.S. monetary policy shock. The U.S. Dollar effective nominal and real exchange rates show small short-term appreciation, and then depreciate. For the U.S. Dollar versus Deutsche Mark bilateral nominal and real exchange rates implied by this set-up, we observe a similar small short-run appreciation. The forward premium impulse responses, both measured as effective forward premia for the United States and as bilateral forward premia for the United States relative to Germany, indicate forward premia in favor of U.S. bonds for about four months. The mostly insignificant nominal and real depreciation of the U.S. Dollar in response to a contractionary U.S. monetary policy shock obtained in the GVECM setting of this step suggests that the Cholesky decomposition based shock identification is rather problematic when applied to a model containing long-run restrictions.

For the fifth step of our counterfactual analysis, we then move to our GVECM set-up with identification restrictions similar to those in Sections 5 and 6 , namely cointegration-based longrun restrictions augmented by as few short-run identification restrictions as necessary, but now unlike in Sections 5 and 6 - we impose cross-country orthogonality of the monetary policy shocks. As Figure 11g shows, for the impulse responses for the nominal and real effective U.S. Dollar exchange rates this yields very similar results as we had obtained in Section 6. (The impulse responses in Figures $11 \mathrm{i}$ and $11 \mathrm{j}$ are obtained using our methodology of Sections 5 and 6, except that they are plotted for a U.S. contractionary monetary policy shock of 50 basis points, as in the previous steps of the counterfactual analysis in this Section.) Also, the impulse response for the effective U.S. forward premium is very similar to the one we had obtained in Section 6 . While there are quantitative differences for the bilateral exchange rate and forward premium responses across the two settings of cross-country orthogonality of the monetary policy shocks being imposed/not imposed, and the results are stronger when cross-country orthogonality of the monetary policy shocks is not imposed (which also is our prefered specification), for the analysis involving effective rates assumptions regarding the presence of cross-country correlation of shocks abroad with U.S. monetary policy shocks clearly are not a factor for the results.

Overall, the findings of our counterfactual analysis strongly suggest that both (i) our accounting for multilateral (rather than just bilateral) cross-country adjustment in response to monetary policy 
shocks, and (ii) our taking advantage of the identifying restrictions for monetary policy shocks implied by long-run relations between the macroeconomic variables under consideration, are of critical relevance in us being able to provide evidence that there is neither a delayed exchange rate overshooting puzzle nor a forward premium puzzle in the adjustment of U.S. Dollar nominal and real exchange rates and forward premia in response to U.S. monetary policy shocks.

\section{Conclusion}

In this paper we have re-considered the effects of monetary policy shocks on exchange rates and forward premia. In the recent empirical literature these effects have been described as puzzling, in that they would include delayed overshooting of the exchange rate as well as persistent deviations from uncovered interest parity. We have constructed an empirical model that in particular (i) allows for simultaneous multi-country adjustments in response to monetary policy shocks, and (ii) takes advantage of the identifying restrictions for monetary policy shocks implied by long-run relations between the macroeconomic variables under consideration. Using monthly data from 1978 to 2006 for a panel of nine industrial economies (Australia, Canada, France, Germany, Italy, Japan, New Zealand, United Kingdom, and the United States), we have found that U.S. Dollar effective and bilateral real exchange rates appreciate almost on impact after a contractionary U.S. monetary policy shock, and that there is no delay in the overshooting of the U.S. Dollar. Furthermore, there is no persistent significant forward premium and the price puzzle is at most weakly present. These results are consistent with the real exchange rate effects of monetary policy shocks in sticky price open economy macroeconomic models, though the results of this paper also suggest that the latter models should be specified so as to capture simultaneous multi-country adjustments to shocks. 


\section{Appendix A: Data Definitions and Sources}

The following are the data definitions and sources for the variables used in the empirical analysis of the paper:

\begin{tabular}{|l|l|l|l|}
\hline Variable & Description & Source & Notes \\
\hline$y$ & $\begin{array}{l}\text { Index of real industrial } \\
\text { production }\end{array}$ & $\begin{array}{l}\text { International Financial } \\
\text { Statistics (IFS) }\end{array}$ & $\begin{array}{l}\text { The series for Australia, France, the United Kingdom and the United } \\
\text { States were not available in seasonally adjusted form from the IFS, } \\
\text { and were seasonally adjusted by the authors. }\end{array}$ \\
\hline$P$ & $\begin{array}{l}\text { Index of consumer } \\
\text { prices }\end{array}$ & IFS & $\begin{array}{l}\text { The price series for Australia and New Zealand involve authors' } \\
\text { interpolation from quarterly series. }\end{array}$ \\
\hline$P^{o}$ & $\begin{array}{l}\text { Trade-weighted } \\
\text { effective nominal } \\
\text { exchange rates }\end{array}$ & IFS and OECD & $\begin{array}{l}\text { The effective exchange rates were computed by the authors } \\
\text { combining bilateral nominal exchange rates from the IFS with bilateral } \\
\text { import and export data for the sample of nine countries from the } \\
\text { OECD. The effective exchange rates are not the multilateral effective } \\
\text { nominal exchange rates reported in the IFS. }\end{array}$ \\
\hline$P^{c}$ & $\begin{array}{l}\text { Spot world market oil } \\
\text { price }\end{array}$ & $\begin{array}{l}\text { Federal Reserve Bank } \\
\text { of St. Louis }\end{array}$ & $\begin{array}{l}\text { International Monetary } \\
\text { index (agricultural raw } \\
\text { materials) }\end{array}$ \\
\hline
\end{tabular}

\begin{tabular}{|l|l|l|}
\hline Variable: $R^{m}$ & Description & Source \\
\hline Australia & Official cash rate & Australian Reserve Bank \\
\hline Canada & Bank of Canada overnight rate & IFS \\
\hline France & Until December 1998: overnight money market rate; from January 1999: EONIA & IFS \\
\hline Germany & Until December 1998: overnight money market rate; from January 1999: EONIA & IFS \\
\hline Italy & Until December 1998: overnight money market rate; from January 1999: EONIA & IFS \\
\hline Japan & Overnight call rate & IFS \\
\hline New Zealand & Until December 1998: discount rate; from January 1999: official cash rate & IFS \\
\hline United Kingdom & Official bank rate & Bank of England \\
\hline United States & Federal funds rate & IFS \\
\hline
\end{tabular}

\begin{tabular}{|c|c|c|c|}
\hline Variable: $R^{S}$ & Description & \begin{tabular}{|l|} 
Source \\
\end{tabular} & Notes \\
\hline Australia & $\begin{array}{l}\text { Treasury bill rate } / 90 \text { days } \\
\text { bank bill rate }\end{array}$ & IFS & $\begin{array}{l}\text { Until May 2002: treasury bill rate; from June 2002: } 90 \text { days bank bill } \\
\text { rate (no observations on treasury bill rate). }\end{array}$ \\
\hline Canada & Treasury bill rate & IFS & \\
\hline France & $\begin{array}{l}\text { Treasury bill rate / EU } \\
\text { refinancing rate }\end{array}$ & IFS & $\begin{array}{l}\text { Until September 2004: treasury bill rate; from October 2004: EU } \\
\text { refinancing rate (no observations on treasury bill rate). }\end{array}$ \\
\hline Germany & Treasury bill rate & IFS & \\
\hline Italy & Treasury bill rate & IFS & \\
\hline Japan & $\begin{array}{l}2 \text { months treasury bill rate / } \\
89-90 \text { days domestic } \\
\text { certificate rate }\end{array}$ & Bank of Japan & $\begin{array}{l}\text { Until December 1995: } 2 \text { months treasury bill rate; from January } \\
\text { 1996: } 89-90 \text { days domestic certificate rate. }\end{array}$ \\
\hline New Zealand & $\begin{array}{l}\text { New issue } 3 \text { months bill rate } / \\
90 \text { days bank bill rate }\end{array}$ & $\begin{array}{l}\text { IFS / Reserve Bank } \\
\text { of New Zealand }\end{array}$ & $\begin{array}{l}\text { Until December 1984: new issue } 3 \text { months bill rate; from January } \\
\text { 1985: } 90 \text { days bank bill rate (no observations on } 3 \text { months bill rate). }\end{array}$ \\
\hline United Kingdom & 3 months treasury bill rate & Bank of England & \\
\hline United States & Treasury bill rate & IFS & \\
\hline
\end{tabular}


Appendix B: Cointegrating Relations for the United States, and Tests for Long-Run Uncovered Interest and Purchasing Power Parity for All Countries

Cointegrating Vectors for the United States Component of the GVECM

\begin{tabular}{|l|c|}
\hline $\begin{array}{l}\text { Cointegrating } \\
\text { Relation \#1 }\end{array}$ & $0.01 t+1.00 y_{t-1}+0.00 P_{t-1}+0.00 R_{t-1}^{m}-2.79 R_{t-1}-1.89 Q_{t-1}+0.53 y_{t-1}^{*}-3.92 P_{t-1}^{*}+9.18 R_{t-1}^{s^{*}}-1.13 Q_{t-1}^{*}+0.45 P_{t-1}^{o}+0.18 P_{t-1}^{c} \sim I(0) ;$ \\
\hline $\begin{array}{l}\text { Cointegrating } \\
\text { Relation \#2 }\end{array}$ & $-0.01 t+0.00 y_{t-1}+1.00 P_{t-1}+0.00 R_{t-1}^{m}-0.56 R_{t-1}+0.81 Q_{t-1}-0.22 y_{t-1}^{*}+0.76 P_{t-1}^{*}-3.12 R_{t-1}^{s^{*}}+0.41 Q_{t-1}^{*}-0.12 P_{t-1}^{o}-0.05 P_{t-1}^{c} \sim I(0) ;$ \\
\hline $\begin{array}{l}\text { Cointegrating } \\
\text { Relation \#3 }\end{array}$ & $0.00 t+0.00 y_{t-1}+0.00 P_{t-1}+1.00 R_{t-1}^{m}-1.20 R_{t-1}+0.21 Q_{t-1}-0.11 y_{t-1}^{*}+0.40 P_{t-1}^{*}-0.73 R_{t-1}^{s^{*}}+0.11 Q_{t-1}^{*}-0.02 P_{t-1}^{o}-0.01 P_{t-1}^{c} \sim I(0)$. \\
\hline
\end{tabular}

The cointegrating relations are identified using Johansen's normalization procedure.

Tests for Long-Run Uncovered Interest and Purchasing Power Parity

\begin{tabular}{|c|c|c|c|c|c|c|c|c|c|}
\hline & Australia & Canada & France & Germany & Italy & Japan & $\begin{array}{c}\text { New } \\
\text { Zealand }\end{array}$ & $\begin{array}{c}\text { United } \\
\text { Kingdom }\end{array}$ & $\begin{array}{l}\text { United } \\
\text { States }\end{array}$ \\
\hline $\begin{array}{l}\text { Uncovered Interest and } \\
\text { Purchasing Power Parity }\end{array}$ & 0.00 & 0.00 & 0.00 & 0.00 & 0.00 & 0.00 & 0.00 & 0.00 & 0.00 \\
\hline
\end{tabular}

The reported $p$-values are for likelihood ratio tests of the overidentifying restrictions on the cointegrating relations implied by Uncovered Interest and Purchasing Power Parity.

Figure 1: The Delayed Exchange Rate Overshooting and Forward Premium Puzzles
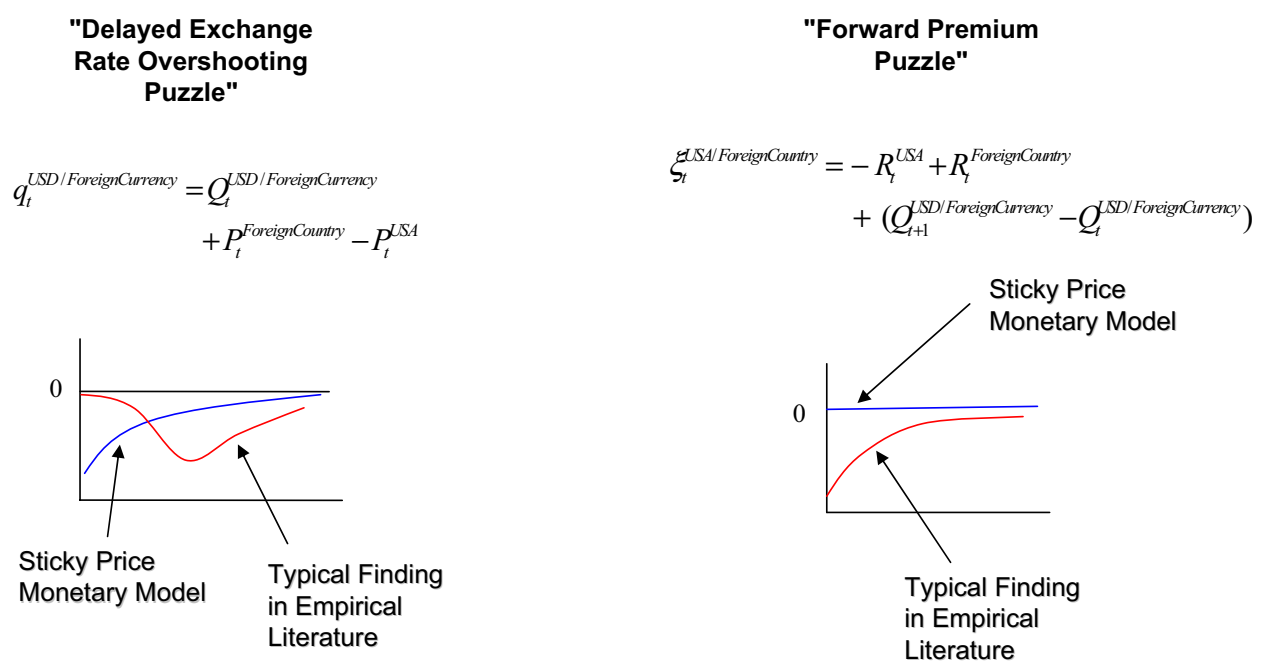
Figure 2: Key Results of Eichenbaum and Evans (1995)
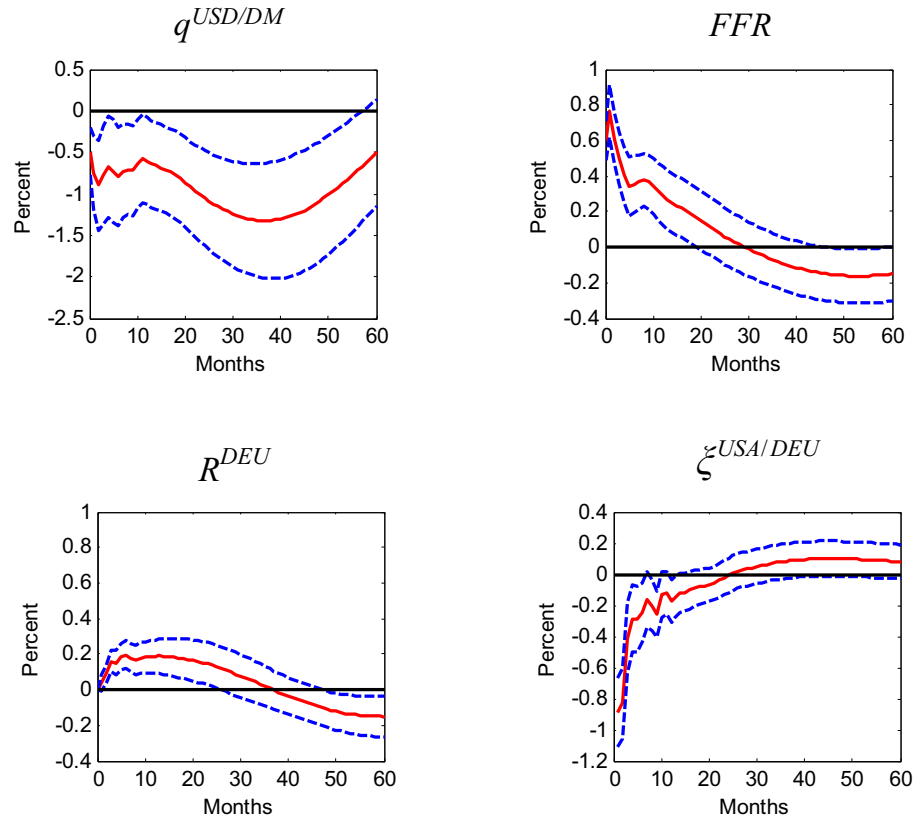

Figure 3: Impulse Response Functions for Monetary Policy Indicator in Response to One-Standard Error U.S. Monetary Policy Shock
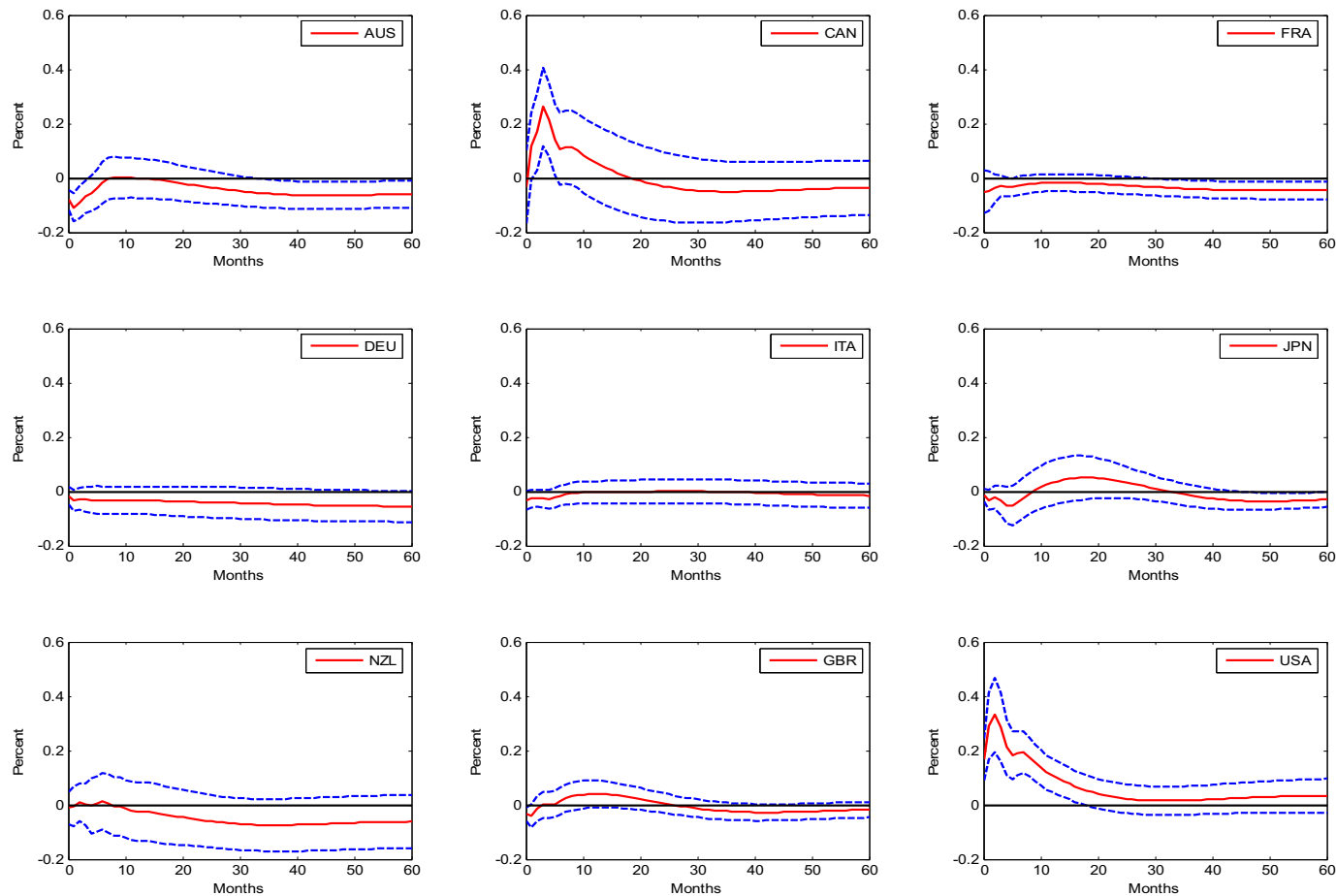
Figure 4: Impulse Response Functions for Short-Term Interest Rate Differential in Response to One-Standard Deviation U.S. Monetary Policy Shock
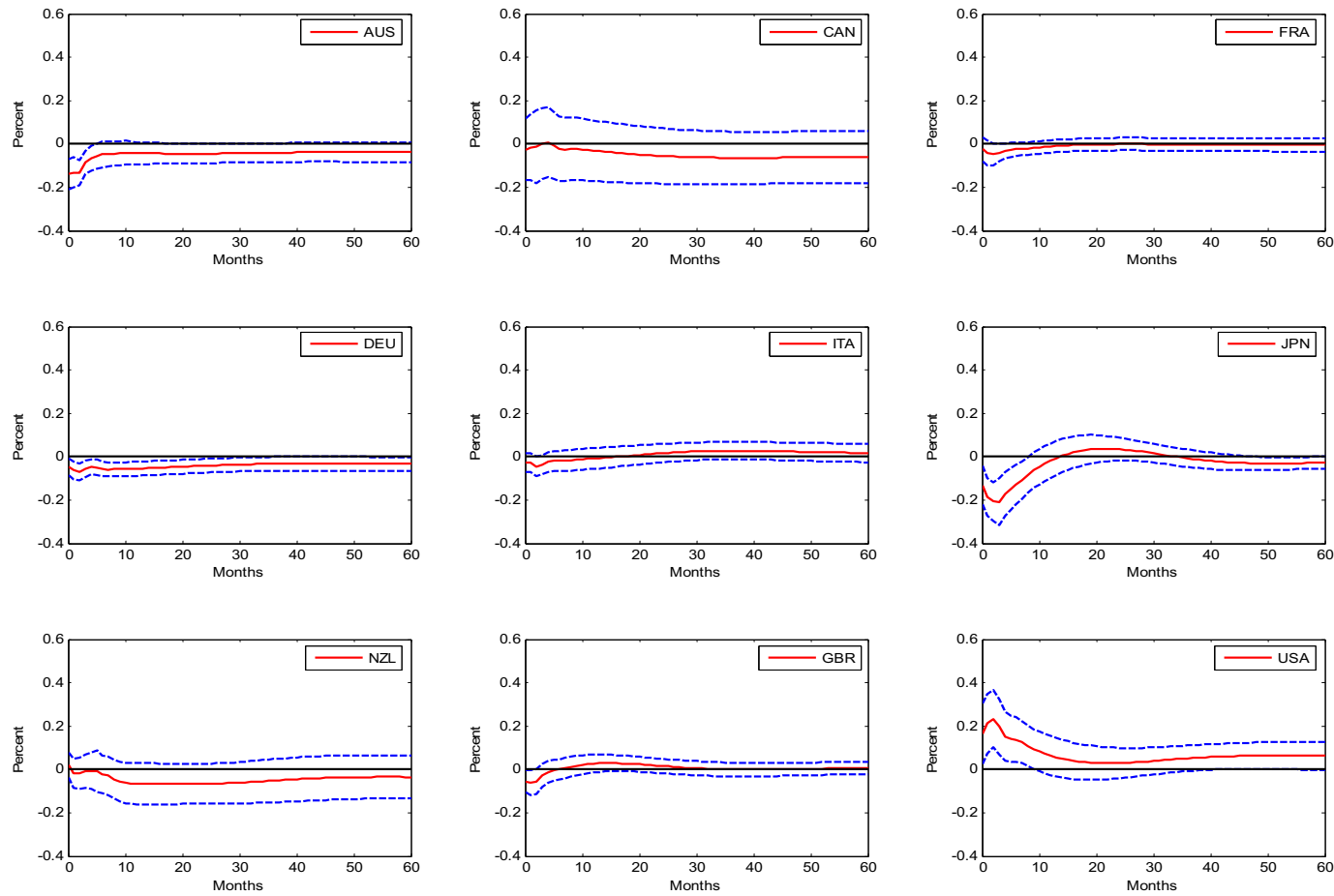

Figure 5a: Impulse Response Functions for Nominal Effective Exchange Rates in Response to One-Standard Deviation U.S. Monetary Policy Shock
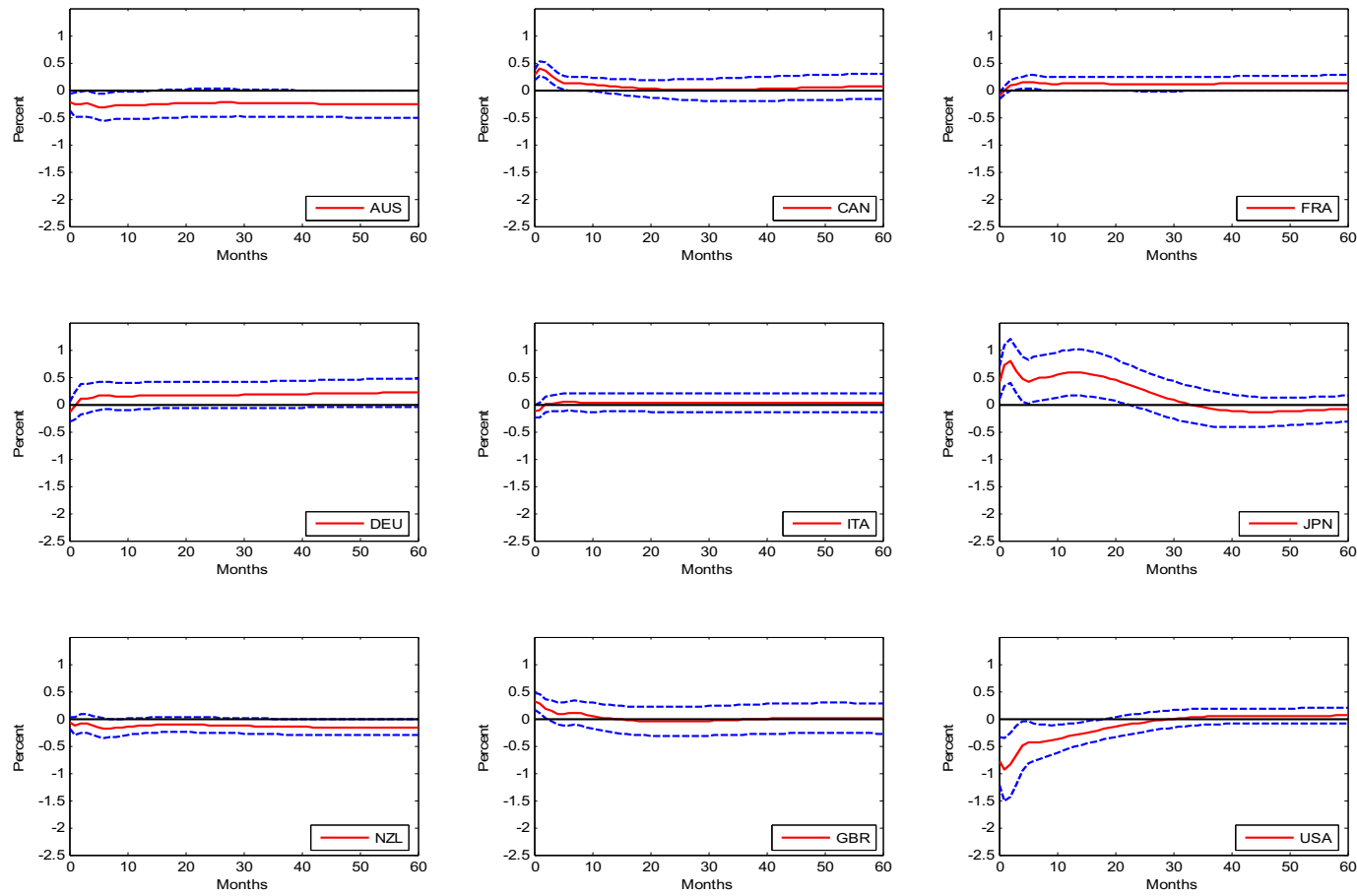
Figure 5b: Impulse Response Function for U.S. Dollar Nominal Effective Exchange Rate in Response to One-Standard Deviation U.S. Monetary Policy Shock

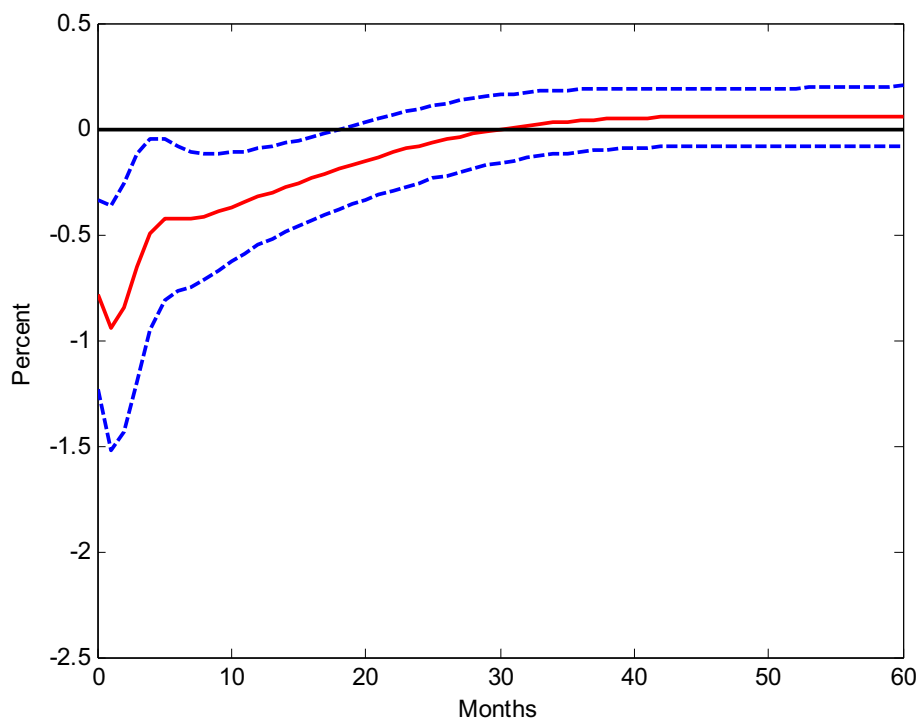

Figure 6a: Impulse Response Functions for Real Effective Exchange Rates in Response to One-Standard Deviation U.S. Monetary Policy Shock
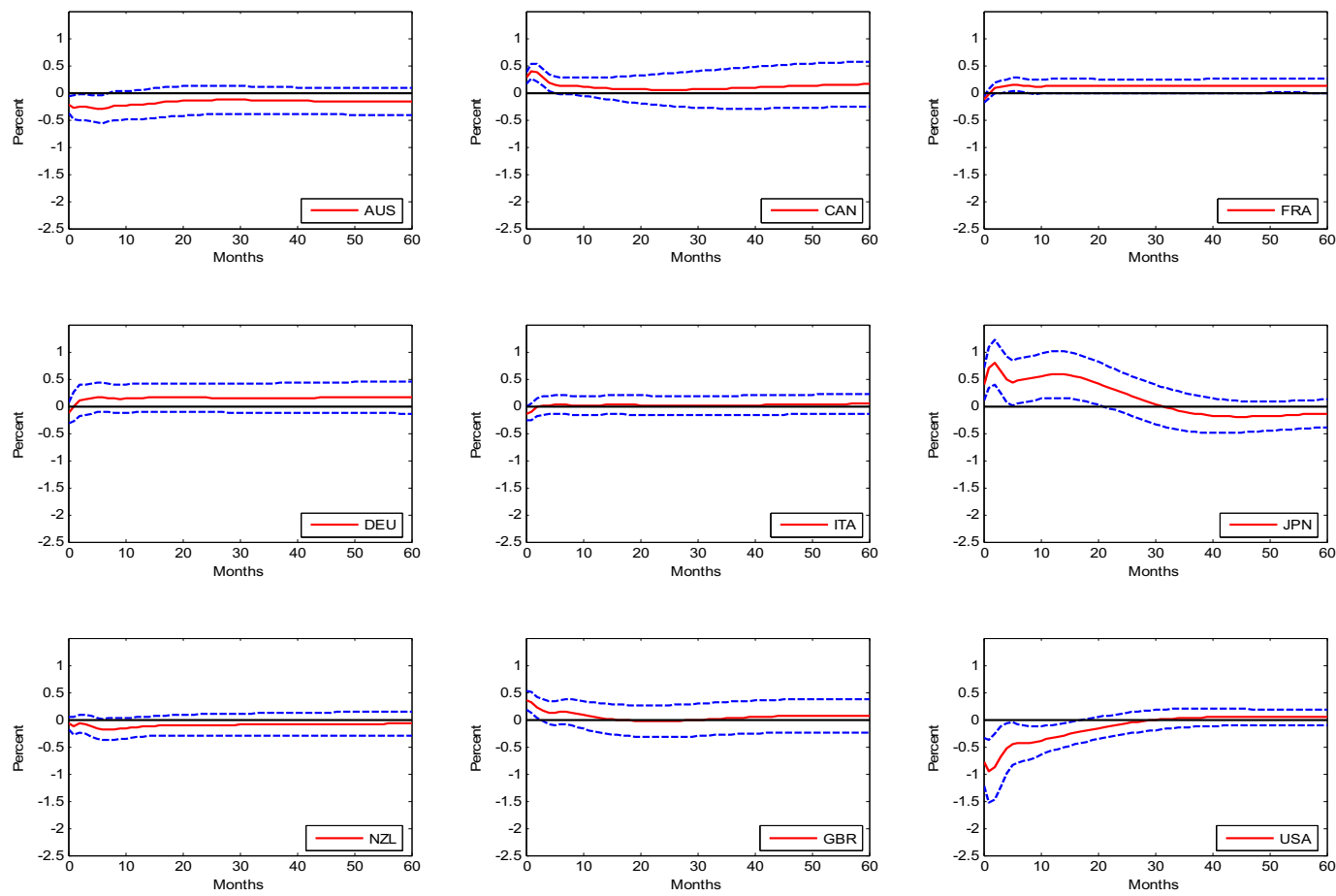
Figure 6b: Impulse Response Function for U.S. Dollar Real Effective Exchange Rate in Response to One-Standard Deviation U.S. Monetary Policy Shock

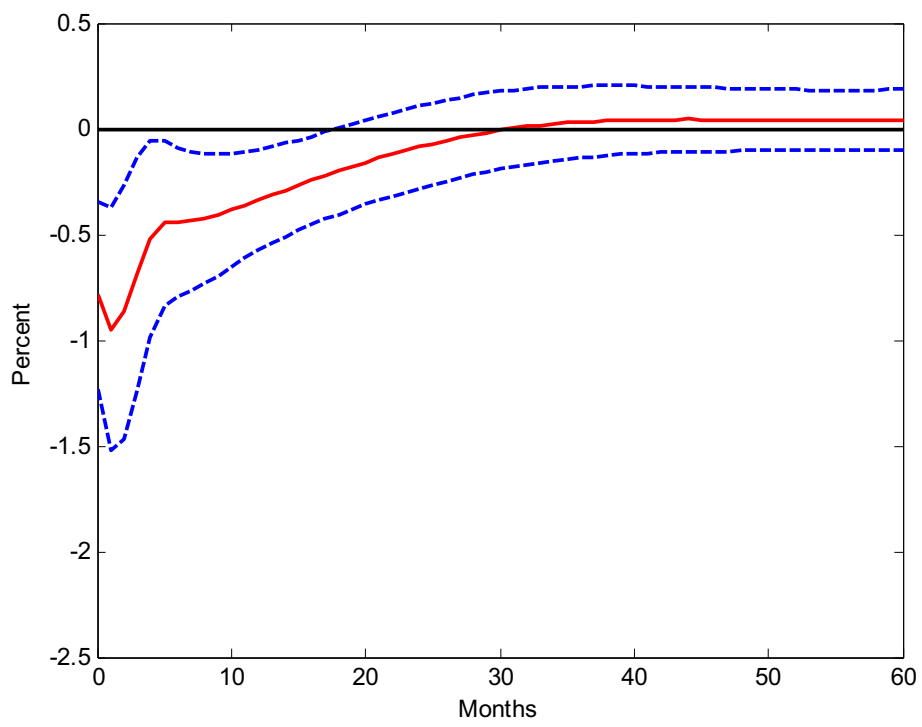

Figure 7a: Impulse Response Functions for Effective Forward Premia in Response to One-Standard Deviation U.S. Monetary Policy Shock
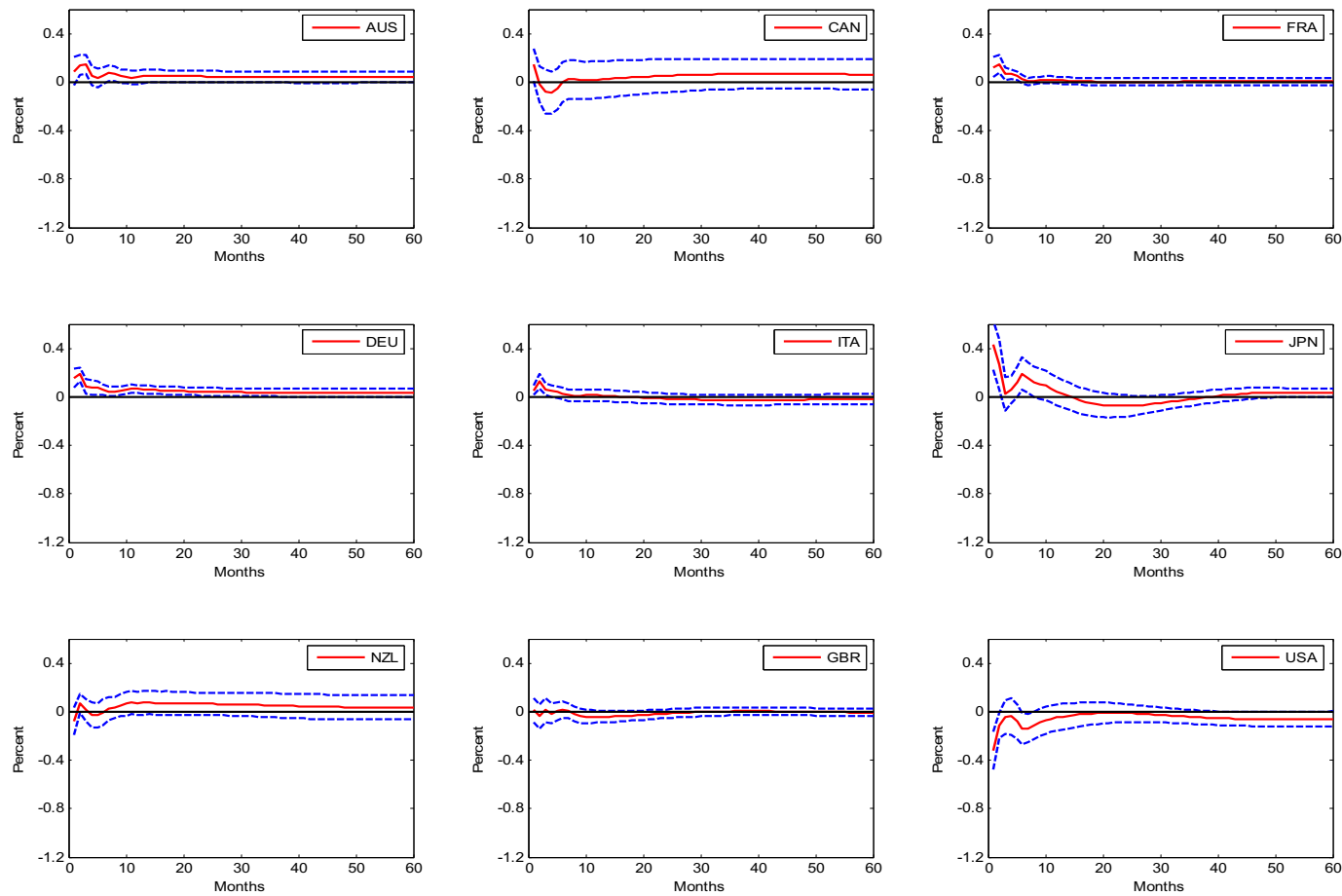
Figure 7b: Impulse Response Function for U.S. Effective Forward Premium in Response to One-Standard Deviation U.S. Monetary Policy Shock

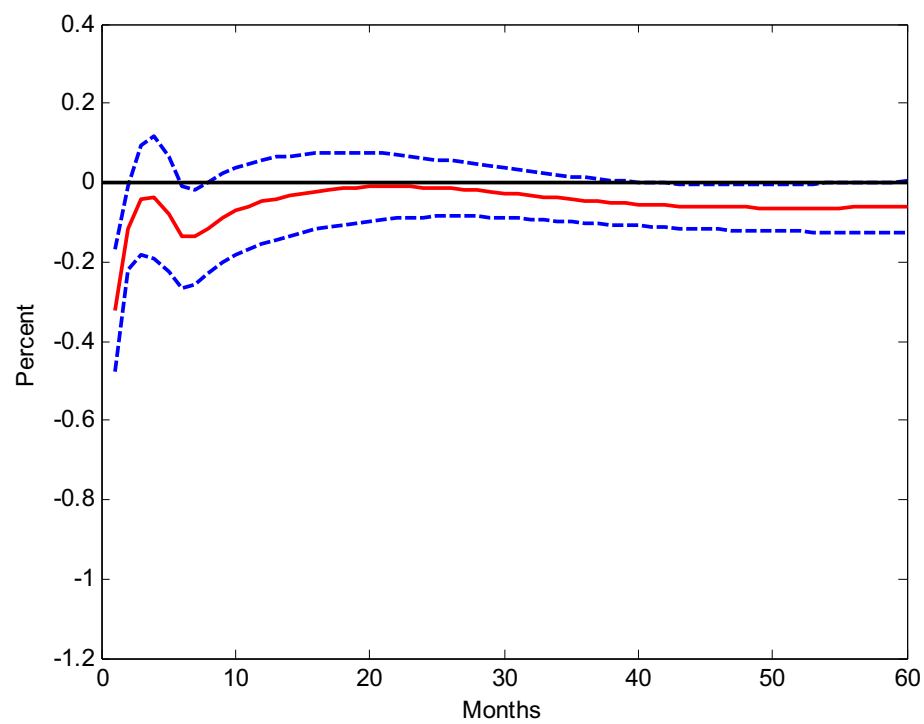

Figure 8: Impulse Response Functions for Prices in Response to One-Standard Deviation U.S. Monetary Policy Shock
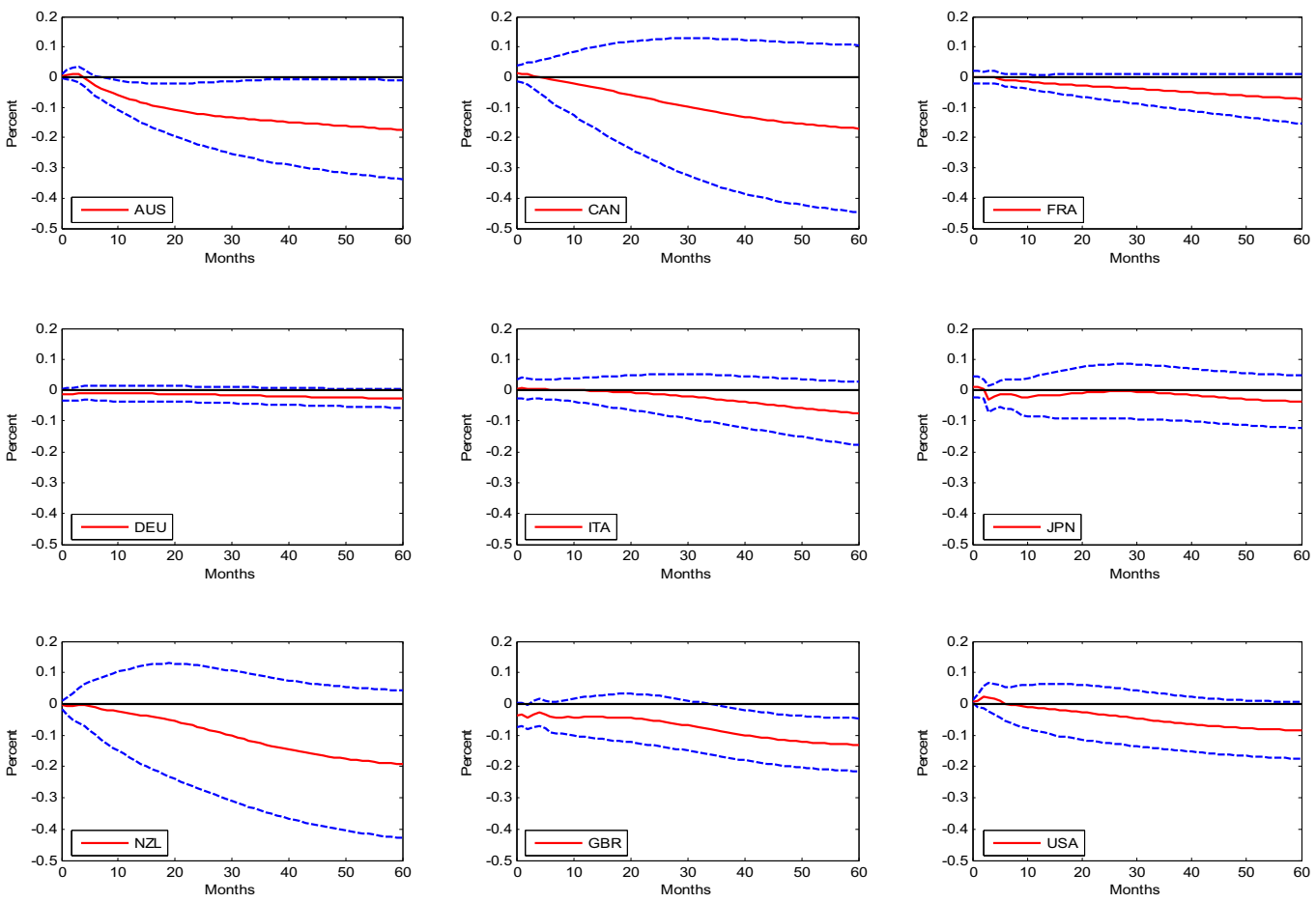
Figure 9: Comparison of Some Key Results

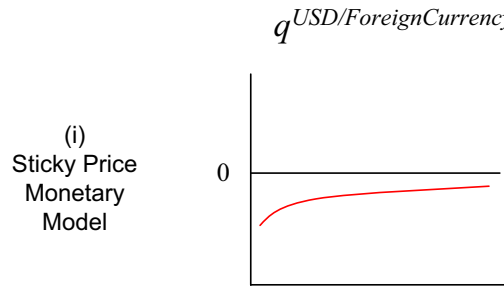

$R^{U S A}-R^{\text {ForeignCountry }}$

0

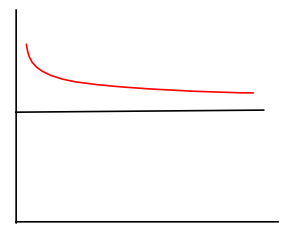

$\xi^{U S A / F o r e i g n C o u n t r y}$

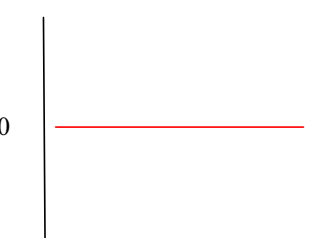

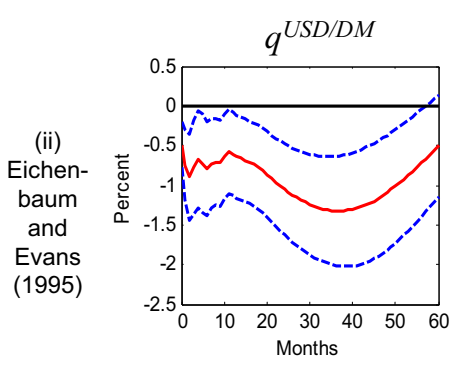
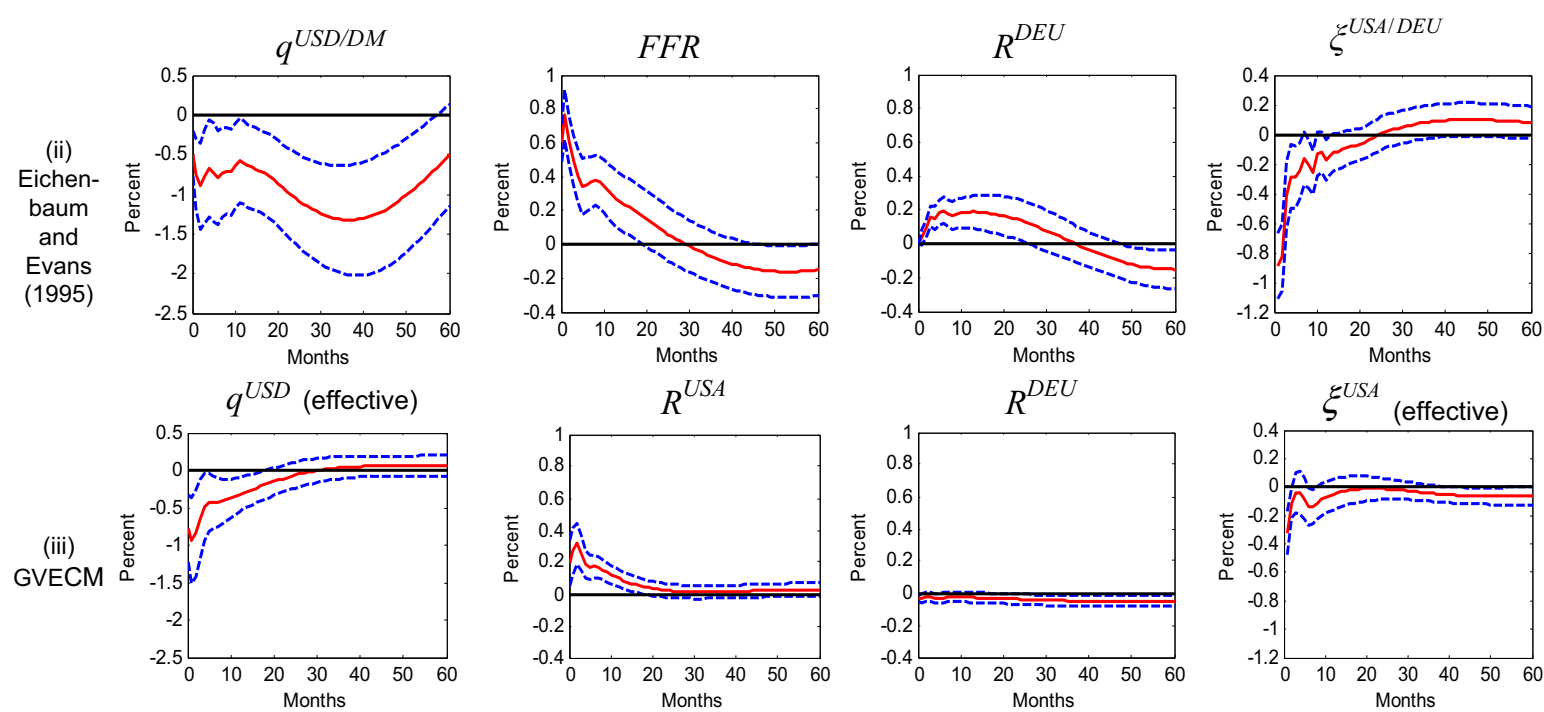

Figure 10: Impulse Response Function for U.S. Dollar Real Effective and Bilateral Exchange Rates in Response to One-Standard Deviation Foreign Monetary Policy Shocks
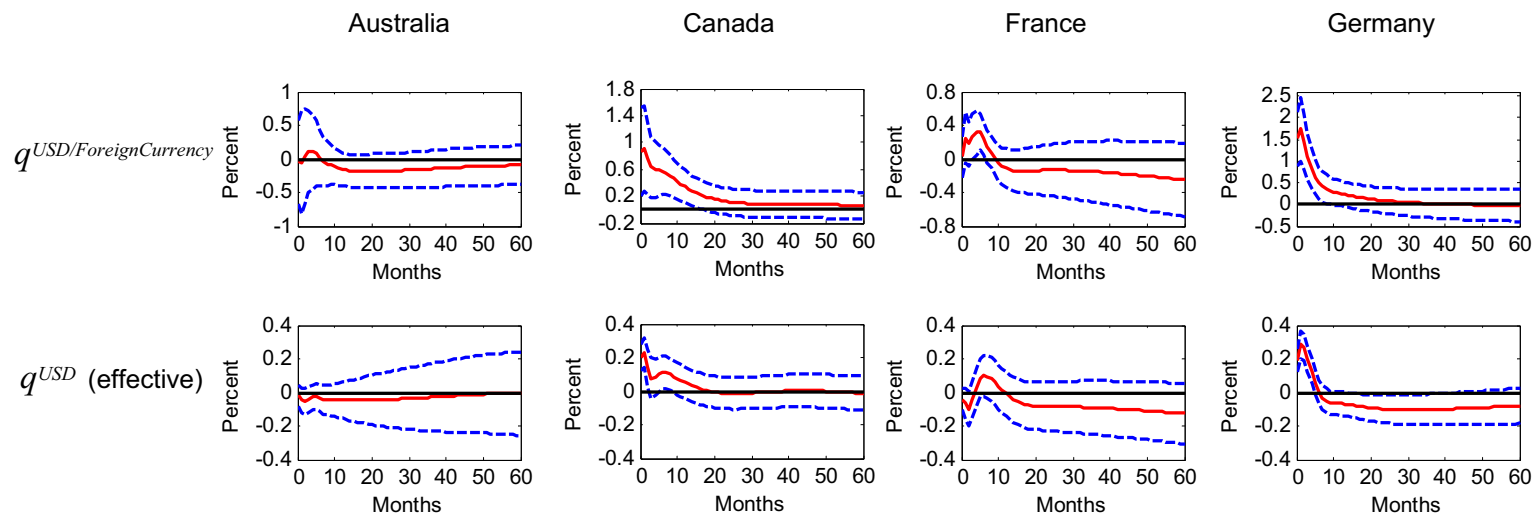

Italy
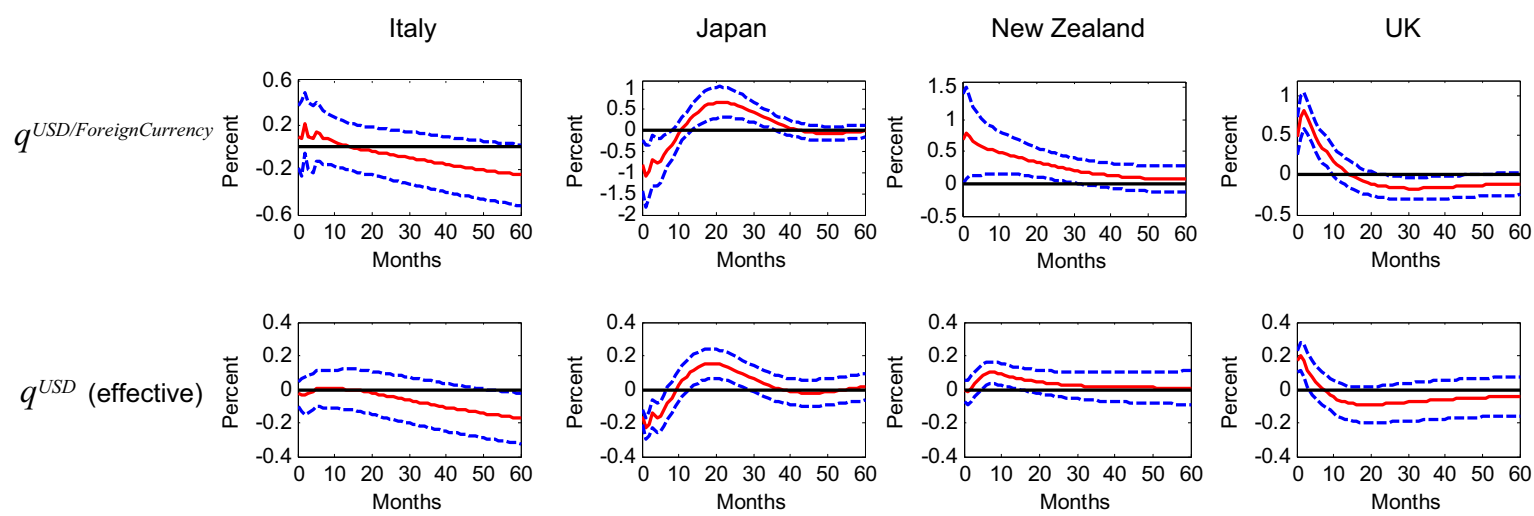
Figure 11a: Comparison of Results through "Counterfactual Analysis"

Step 1: Eichenbaum and Evans (1995) Specification for Extended Data Set

$q^{U S D / D M}$

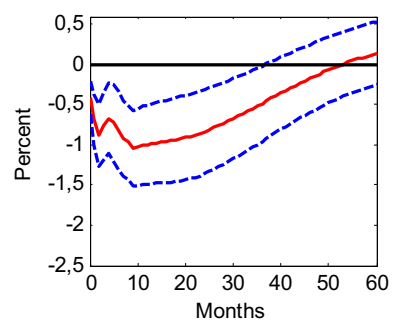

FFR

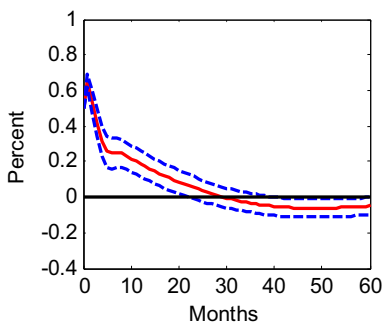

$Q^{U S D / D M}$

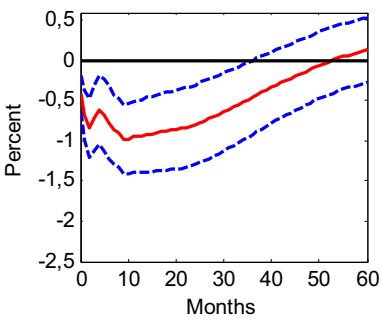

$R^{D E U}$
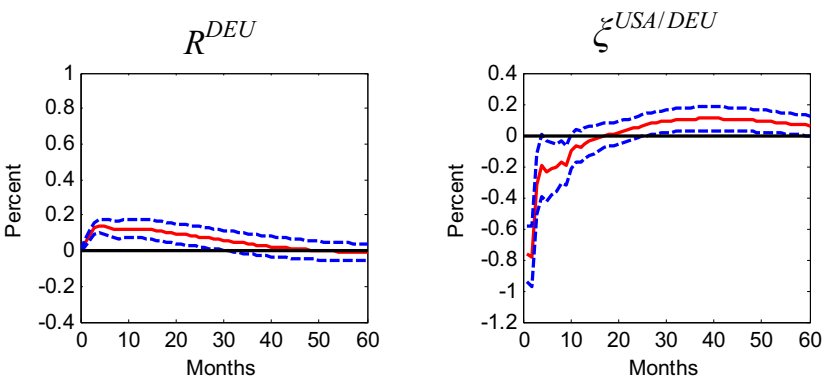

Figure 11b: Comparison of Results through "Counterfactual Analysis"

Step 2: Augmenting Eichenbaum and Evans (1995) Specification to Capture this Paper's Specification of Domestic and Foreign Variables
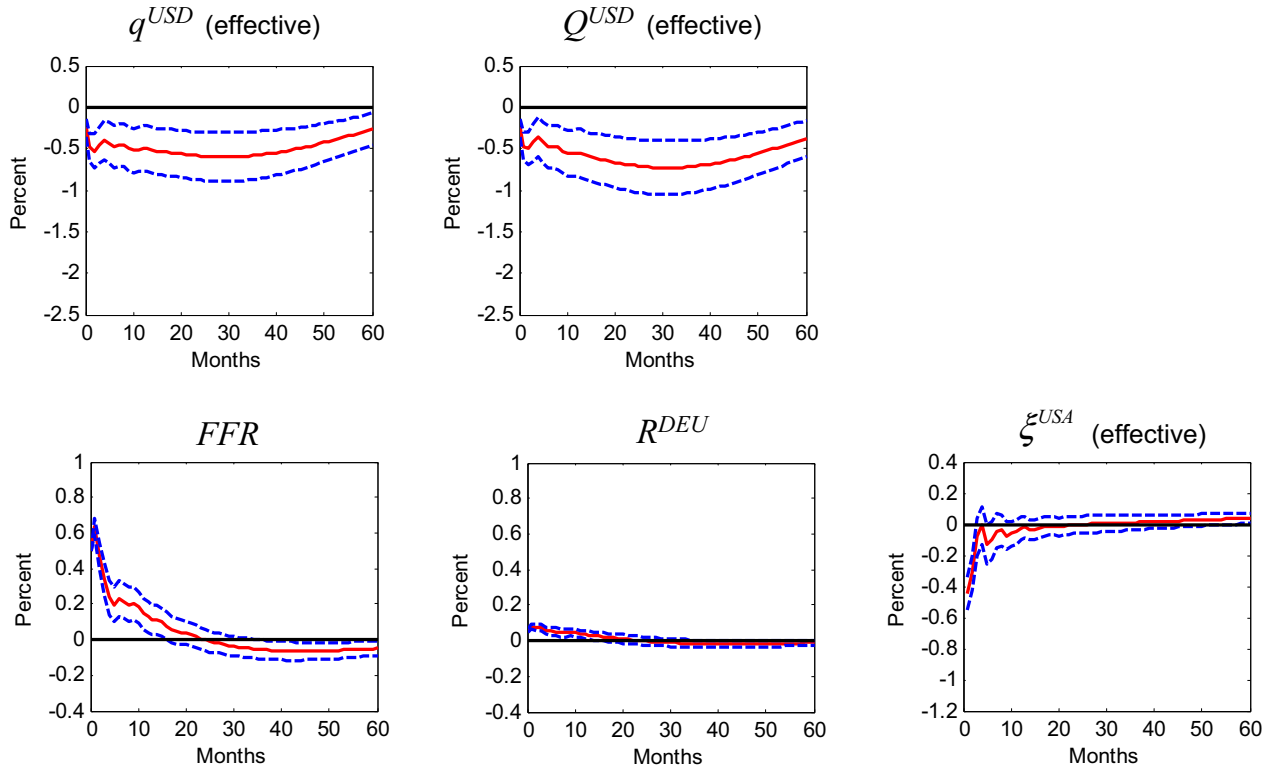
Figure 11c: Comparison of Results through "Counterfactual Analysis"

Step 3: Considering a GVAR Specification (Same Variables as in GVECM, Cholesky Decomposition Based Shock Identification) - Effective Exchange Rates and Forward Premium
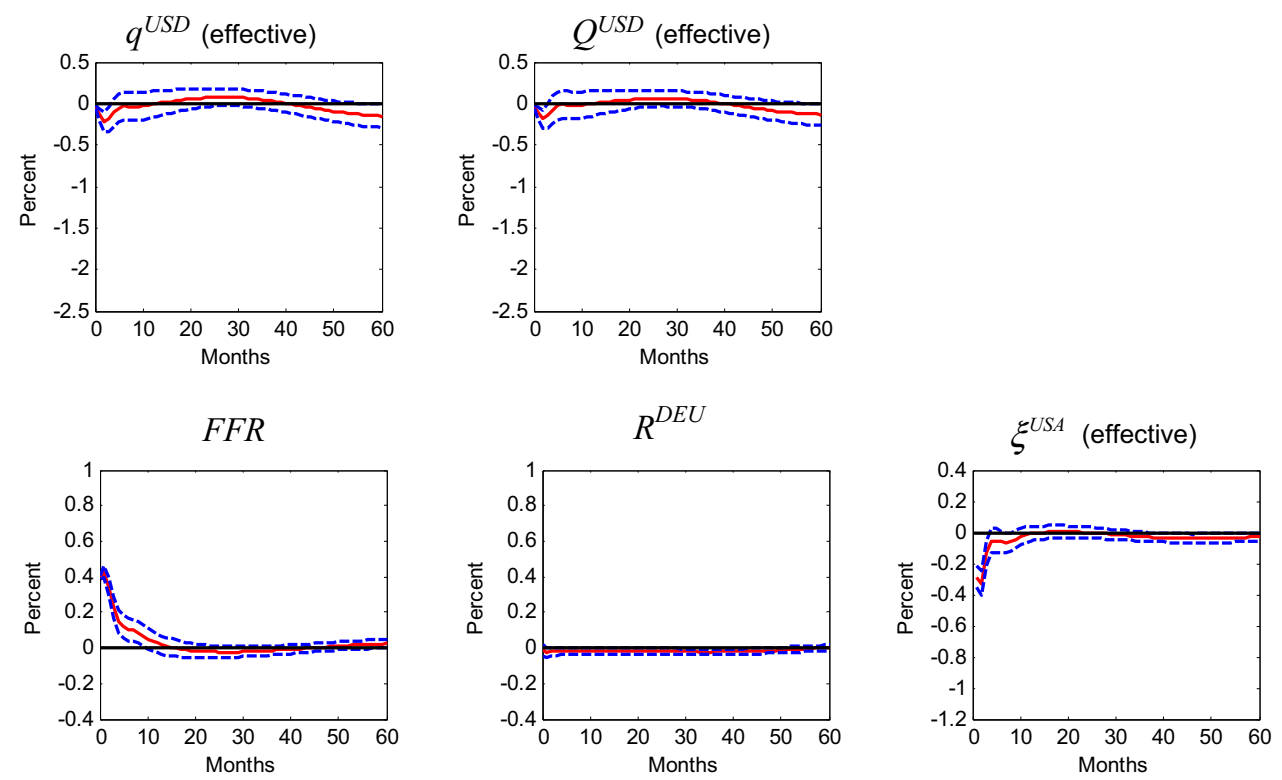

Figure 11d: Comparison of Results through "Counterfactual Analysis"

Step 3: Considering a GVAR Specification (Same Variables as in GVECM, Cholesky Decomposition Based Shock Identification) - Bilateral Exchange Rates and Forward Premium
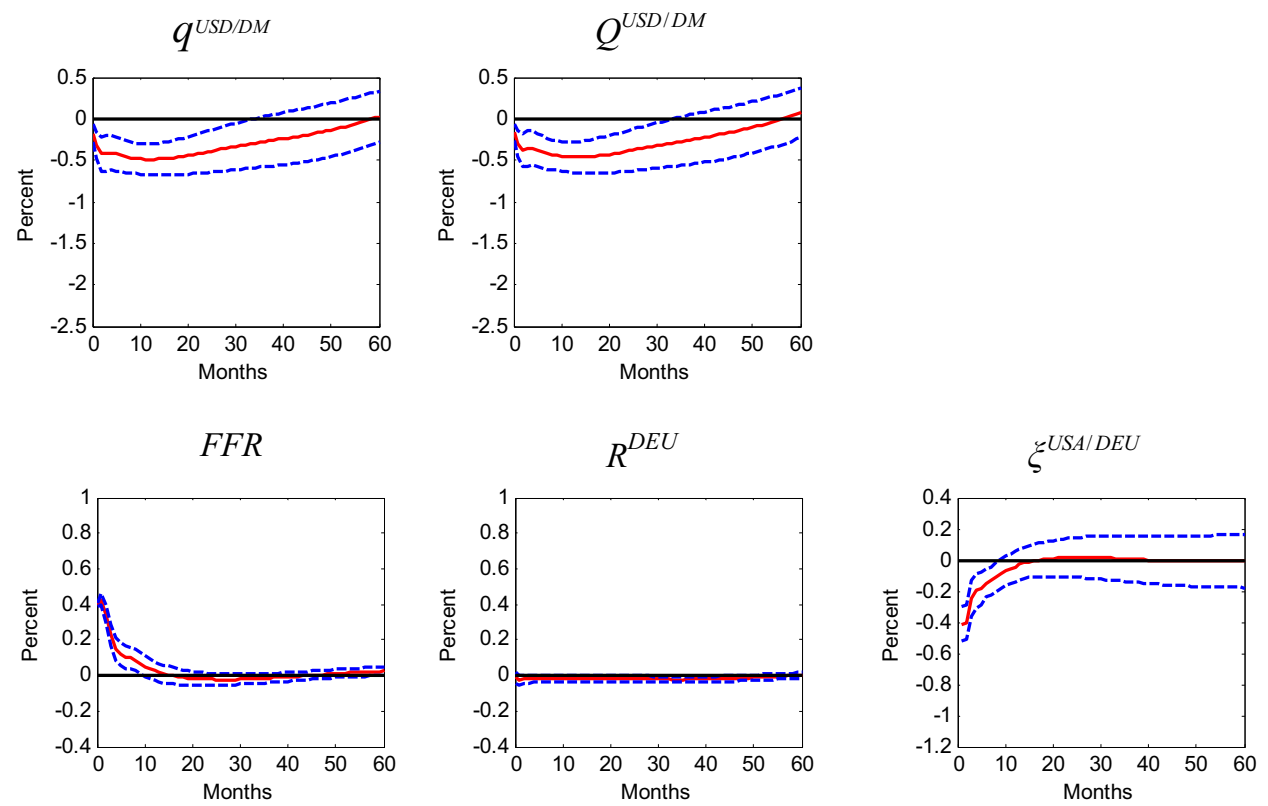
Figure 11e: Comparison of Results through "Counterfactual Analysis"

Step 4: GVECM Specification (Cholesky Decomposition Based Shock Identification) Effective Exchange Rates and Forward Premium
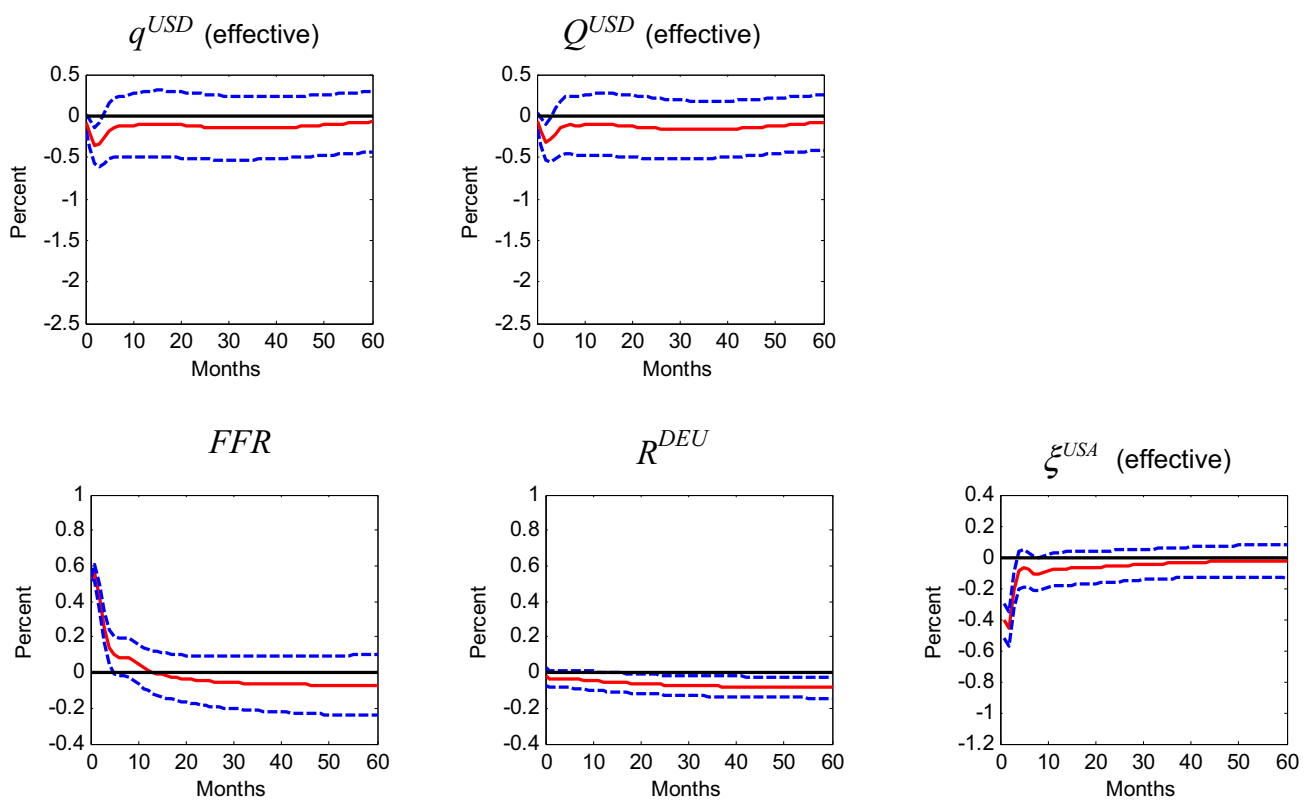

Figure 11f: Comparison of Results through "Counterfactual Analysis"

Step 4: GVECM Specification (Cholesky Decomposition Based Shock Identification) Bilateral Exchange Rates and Forward Premium
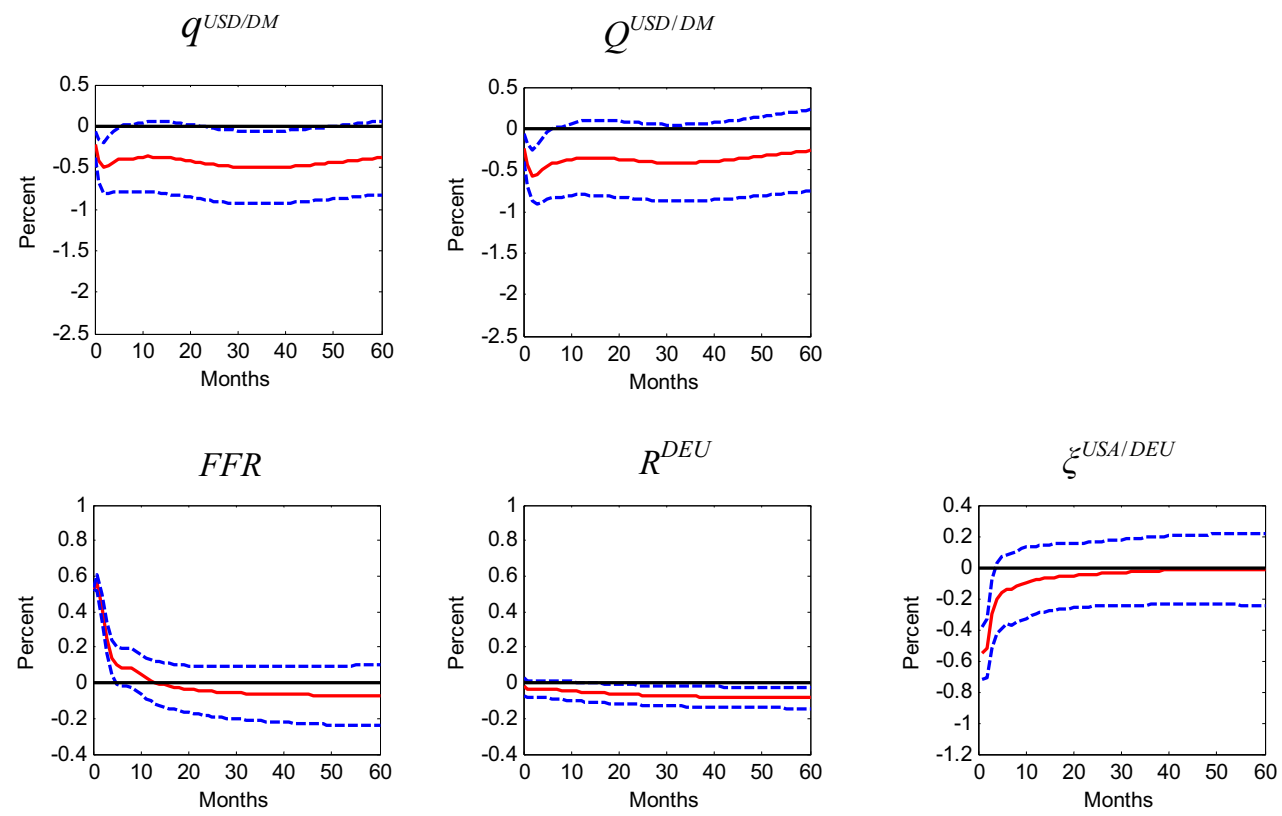
Figure 11g: Comparison of Results through "Counterfactual Analysis"

Step 5: GVECM Specification (Cross-Country Orthogonality of U.S. Monetary Policy Shocks) - Effective Exchange Rates and Forward Premium

$q^{U S D}$ (effective)

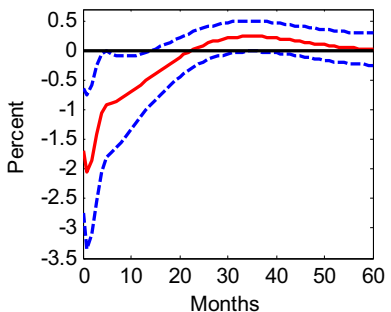

FFR

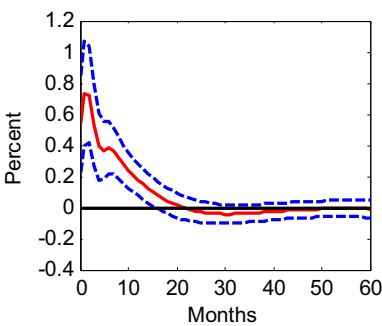

$Q^{U S D}$ (effective)

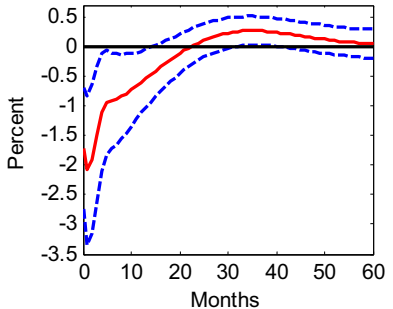

$R^{D E U}$

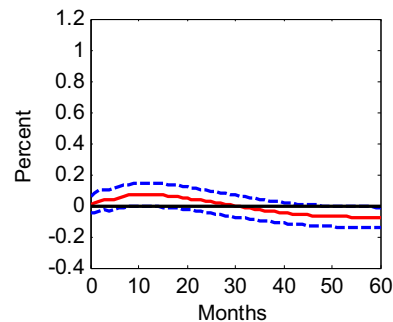

$\xi^{U S A}$ (effective)

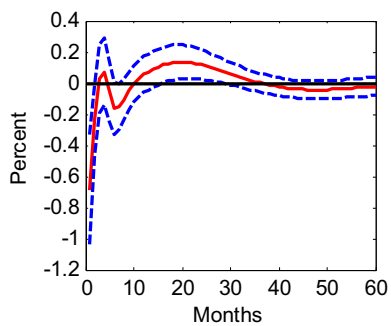

Figure 11h: Comparison of Results through "Counterfactual Analysis"

Step 5: GVECM Specification (Cross-Country Orthogonality of U.S. Monetary Policy Shocks) - Bilateral Exchange Rates and Forward Premium
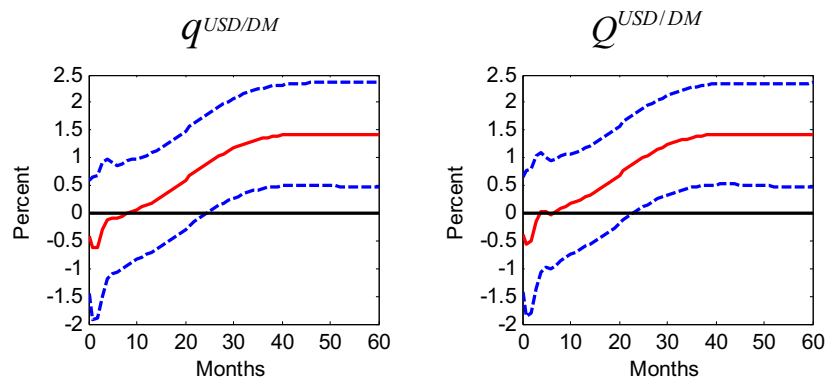

FFR
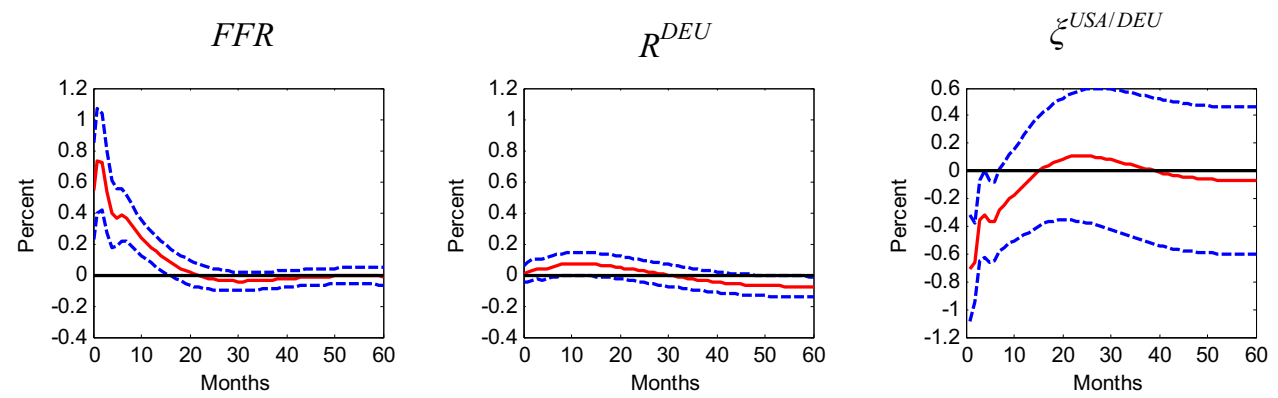
Figure 11i: Comparison of Results through "Counterfactual Analysis"

Step 6: GVECM Specification - Effective Exchange Rates and Forward Premium
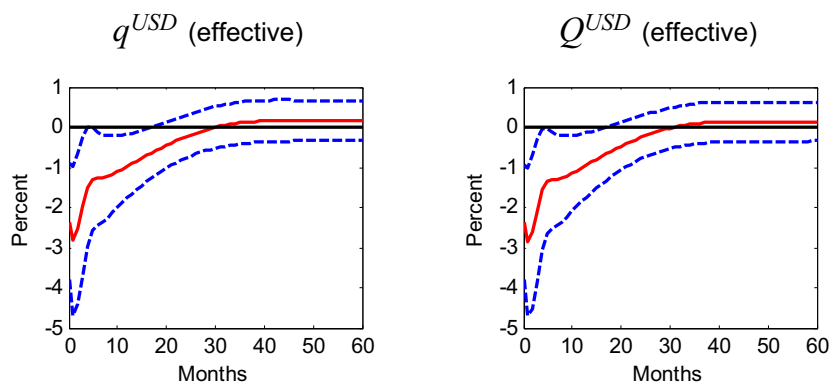

FFR
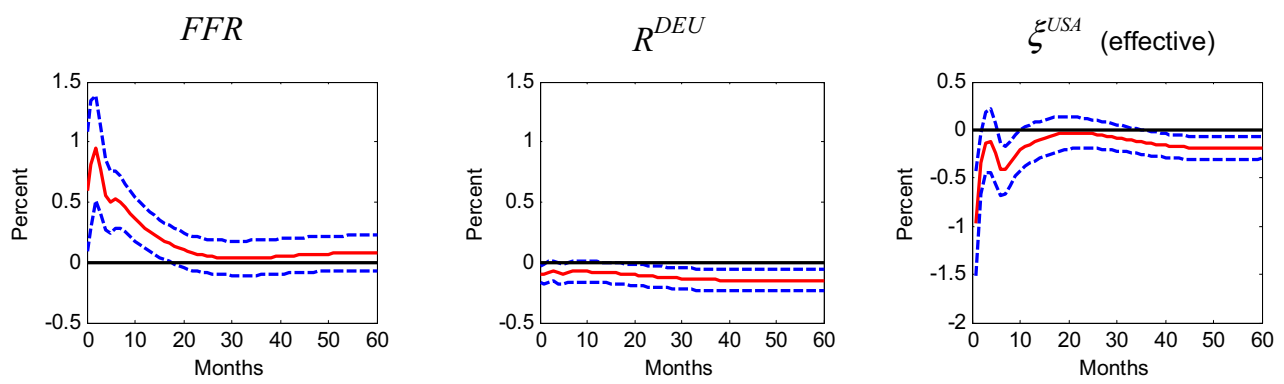

Figure 11j: Comparison of Results through "Counterfactual Analysis"

Step 6: GVECM Specification - Bilateral Exchange Rates and Forward Premium

$q^{U S D / D M}$

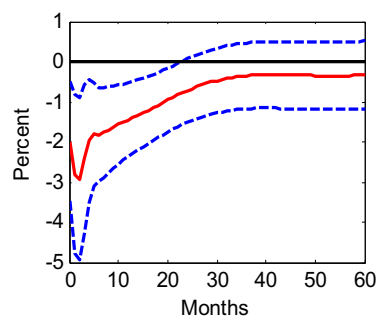

FFR

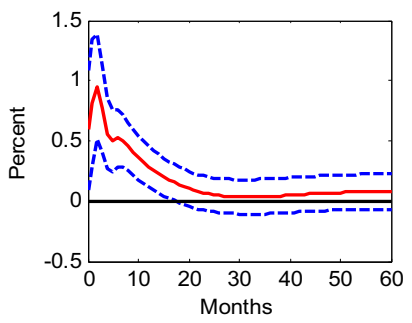

$Q^{U S D / D M}$

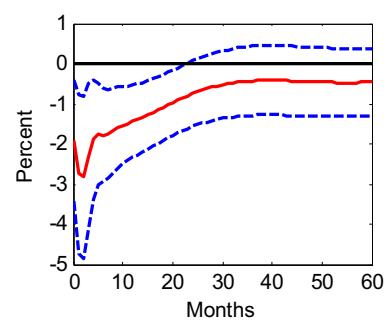

$R^{D E U}$

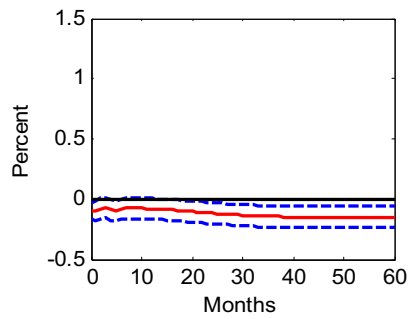

$\xi^{U S A / D E U}$

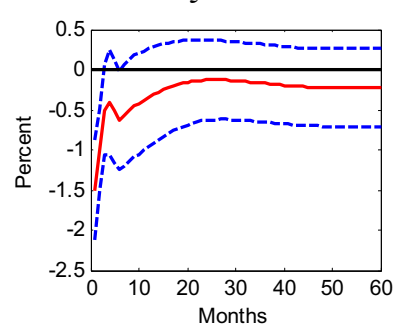




\section{References}

[1] Andersen, T.M., and N.C. Beier (2005): International Transmission of Transitory and Persistent Monetary Shocks under Imperfect Information, Journal of International Economics, 66, pp. 485-507.

[2] Armour, J., W. Engert, and B.S.C. Fung (1996): Overnight Rate Innovations as a Measure of Monetary Policy Shocks in Vector Autoregressions, Working Paper, Bank of Canada.

[3] Bacchetta, P. and E. van Wincoop (2006): Random Walk Expectations and the Forward Discount Puzzle, American Economic Review, 97, pp. 346-350.

[4] Benigno, G. (2004): Real Exchange Rate Persistence and Monetary Policy Rules, Journal of Monetary Economics, 51, pp. 473-502.

[5] Bergin, P.R. (2006): How Well Can the New Open Economy Macroeconomics Explain the Exchange Rate and Current Account? Working Paper, University of California at Davis.

[6] Bernanke, B.S., and I. Mihov (1997): What Does The Bundesbank Target?, European Economic Review, 41, pp. 1025-1053.

[7] Bernanke, B.S., and I. Mihov (1998): Measuring Monetary Policy, Quarterly Journal of Economics, 113, pp. 869-902.

[8] Bjornland, H.C. (2009): Monetary Policy and Exchange Rate Overshooting: Dornbusch Was Right After All, Journal of International Economics, 79, pp. 64-77.

[9] Brueggemann, I. (2003): Measuring Monetary Policy in Germany: A Structural Vector Error Correction Approach, German Economic Review, 4, pp. 307-339.

[10] Clarida, R., and J. Gali (1994): Sources of Real Exchange-Rate Fluctuations: How Important Are Nominal Shocks?, Carnegie-Rochester Conference Series on Public Policy, 41, pp. 1-56.

[11] Croushore, D., and C.L. Evans (2006): Data Revisions and the Identification of Monetary Policy Shocks, Journal of Monetary Economics, 53, pp. 1135-1160,

[12] Cushman, D. O., and T. Zha (1997): Identifying Monetary Policy in a Small Open Economy under Flexible Exchange Rates, Journal of Monetary Economics, 39, pp. 433-448.

[13] De Arcangelis, G., and G. Di Giorgio (1999): Monetary Policy Shocks and Transmission in Italy: A VAR Analysis, Working Paper, Universitat Pompeu Fabra.

[14] Eichenbaum, M., and C. Evans (1995): Some Empirical Evidence on the Effect of Monetary Policy Shocks on Exchange Rates, Quarterly Journal of Economics, 110, pp. 975-1009.

[15] Engel, C. (1996): The Forward Discount Anomaly and the Risk Premium: A Survey of the Recent Experience, Journal of Empirical Finance, 3, pp. 123-192.

[16] Faust, J., and E.M. Leeper (1997): When Do Long-Run Identifying Restrictions Give Reliable Results? Journal of Business and Economic. Statistics, 15, pp. 345-353.

[17] Faust, J., and J.H. Rogers (2003): Monetary Policy's Role in Exchange Rate Behavior, Journal of Monetary Economics, 50, pp. 1403-1424. 
[18] Gourinchas, P.O., and A. Tornell (2004): Exchange Rate Puzzles and Distorted Beliefs, Journal of International Economics, 64, pp. 303-333.

[19] Kilian, L. (1998): Small-Sample Confidence Intervals for Impulse Response Functions, Review of Economics and Statistics, 80, pp. 218-230.

[20] Kim, S. (2005): Monetary Policy, Foreign Exchange Policy, and Delayed Overshooting, Journal of Money, Credit, and Banking, 37, pp. 775-782.

[21] Kim, S., and N. Roubini (2000): Exchange Rate Anomalies in the Industrial Countries: A Solution With a Structural VAR Approach, Journal of Monetary Economics, 45, pp. 561-586.

[22] Landry, A. (2009): Expectations and Exchange Rat Dynamics: A State-Dependent Pricing Approach, Journal of International Economics, 78, pp. 60-71.

[23] Luetkepohl, H. (2007): New Introduction to Multiple Time Series Analysis, Springer Verlag.

[24] McCallum, B.T. (2003): Japanese Monetary Policy, Federal Reserve Bank of Richmond Economic Quarterly, 89, pp. 1-31.

[25] Miyao, R. (2002): The Effects of Monetary Policy in Japan, Journal of Money, Credit and Banking, 34, pp. 376-392.

[26] Okina, K. (1993): Market Operations in Japan: Theory and Evidence, in J. Singleton (Ed.): Japanese Monetary Policy, University of Chicago Press, pp. 31-62.

[27] Pagan, A.R., and M.H. Pesaran (2008): Econometric Analysis of Structural Systems with Permanent and Transitory Shocks, Journal of Economic Dynamics and Control, 32, pp. 3376-3395.

[28] Pesaran, M.H., T. Schuermann, and S.M. Weiner (2004): Modelling Regional Interdependencies Using a Global Error Correcting Macroeconometric Model, Journal of Business and Economic Statistics, 22, pp. $129-162$.

[29] Pesaran, M.H., Y. Shin and R.J. Smith (2000): Structural Analysis of Vector Error Correction Models with Exogenous I(1) Variables, Journal of Econometrics, 97, pp. 293-343.

[30] Scholl, A., and H. Uhlig (2008): New Evidence on the Puzzles: Results from Agnostic Identification on Monetary Policy and Exchange Rates, Journal of International Economics, 76, pp. 1-13.

[31] Steinsson, J. (2008): The Dynamic Behavior of the Real Exchange Rate in Sticky Price Models, American Economic Review, 98, pp. 519-553.

[32] Zellner, A. (1962): An Efficient Method of Estimating Seemingly Unrelated Regressions and Tests for Aggregation Bias, Journal of the American Statistical Association, 57, pp. 348-368. 


\section{CESifo Working Paper Series}

for full list see www.cesifo-group.org/wp

(address: Poschingerstr. 5, 81679 Munich, Germany, office@cesifo.de)

3098 Thomas Moutos and Christos Tsitsikas, Whither Public Interest: The Case of Greece's Public Finance, June 2010

3099 Thomas Eichner and Thorsten Upmann, Labor Markets and Capital Tax Competition, June 2010

3100 Massimo Bordignon and Santino Piazza, Who do you Blame in Local Finance? An Analysis of Municipal Financing in Italy, June 2010

3101 Kyriakos C. Neanidis, Financial Dollarization and European Union Membership, June 2010

3102 Maela Giofré, Investor Protection and Foreign Stakeholders, June 2010

3103 Andrea F. Presbitero and Alberto Zazzaro, Competition and Relationship Lending: Friends or Foes?, June 2010

3104 Dan Anderberg and Yu Zhu, The Effect of Education on Martial Status and Partner Characteristics: Evidence from the UK, June 2010

3105 Hendrik Jürges, Eberhard Kruk and Steffen Reinhold, The Effect of Compulsory Schooling on Health - Evidence from Biomarkers, June 2010

3106 Alessandro Gambini and Alberto Zazzaro, Long-Lasting Bank Relationships and Growth of Firms, June 2010

3107 Jenny E. Ligthart and Gerard C. van der Meijden, Coordinated Tax-Tariff Reforms, Informality, and Welfare Distribution, June 2010

3108 Vilen Lipatov and Alfons Weichenrieder, Optimal Income Taxation with Tax Competition, June 2010

3109 Malte Mosel, Competition, Imitation, and R\&D Productivity in a Growth Model with Sector-Specific Patent Protection, June 2010

3110 Balázs Égert, Catching-up and Inflation in Europe: Balassa-Samuelson, Engel's Law and other Culprits, June 2010

3111 Johannes Metzler and Ludger Woessmann, The Impact of Teacher Subject Knowledge on Student Achievement: Evidence from Within-Teacher Within-Student Variation, June 2010

3112 Leif Danziger, Uniform and Nonuniform Staggering of Wage Contracts, July 2010 
3113 Wolfgang Buchholz and Wolfgang Peters, Equity as a Prerequisite for Stable Cooperation in a Public-Good Economy - The Core Revisited, July 2010

3114 Panu Poutvaara and Olli Ropponen, School Shootings and Student Performance, July 2010

3115 John Beirne, Guglielmo Maria Caporale and Nicola Spagnolo, Liquidity Risk, Credit Risk and the Overnight Interest Rate Spread: A Stochastic Volatility Modelling Approach, July 2010

3116 M. Hashem Pesaran, Predictability of Asset Returns and the Efficient Market Hypothesis, July 2010

3117 Dorothee Crayen, Christa Hainz and Christiane Ströh de Martínez, Remittances, Banking Status and the Usage of Insurance Schemes, July 2010

3118 Eric O'N. Fisher, Heckscher-Ohlin Theory when Countries have Different Technologies, July 2010

3119 Huw Dixon and Hervé Le Bihan, Generalized Taylor and Generalized Calvo Price and Wage-Setting: Micro Evidence with Macro Implications, July 2010

3120 Laszlo Goerke and Markus Pannenberg, 'Take it or Go to Court' - The Impact of Sec. 1a of the German Protection against Dismissal Act on Severance Payments -, July 2010

3121 Robert S. Chirinko and Daniel J. Wilson, Can Lower Tax Rates be Bought? Business Rent-Seeking and Tax Competition among U.S. States, July 2010

3122 Douglas Gollin and Christian Zimmermann, Global Climate Change and the Resurgence of Tropical Disease: An Economic Approach, July 2010

3123 Francesco Daveri and Maria Laura Parisi, Experience, Innovation and Productivity Empirical Evidence from Italy's Slowdown, July 2010

3124 Carlo V. Fiorio and Massimo Florio, A Fair Price for Energy? Ownership versus Market Opening in the EU15, July 2010

3125 Frederick van der Ploeg, Natural Resources: Curse or Blessing?, July 2010

3126 Kaisa Kotakorpi and Panu Poutvaara, Pay for Politicians and Candidate Selection: An Empirical Analysis, July 2010

3127 Jun-ichi Itaya, Makoto Okamura and Chikara Yamaguchi, Partial Tax Coordination in a Repeated Game Setting, July 2010

3128 Volker Meier and Helmut Rainer, On the Optimality of Joint Taxation for NonCooperative Couples, July 2010

3129 Ryan Oprea, Keith Henwood and Daniel Friedman, Separating the Hawks from the Doves: Evidence from Continuous Time Laboratory Games, July 2010 
3130 Mari Rege and Ingeborg F. Solli, The Impact of Paternity Leave on Long-term Father Involvement, July 2010

3131 Olaf Posch, Risk Premia in General Equilibrium, July 2010

3132 John Komlos and Marek Brabec, The Trend of BMI Values by Centiles of US Adults, Birth Cohorts 1882-1986, July 2010

3133 Emin Karagözoğlu and Arno Riedl, Information, Uncertainty, and Subjective Entitlements in Bargaining, July 2010

3134 John Boyd, Gianni De Nicolò and Elena Loukoianova, Banking Crises and Crisis Dating: Theory and Evidence, July 2010

3135 Michael R. Baye, Dan Kovenock and Casper G. de Vries, The Herodotus Paradox, July 2010

3136 Martin Kolmar and Hendrik Rommeswinkel, Group Contests with Complementarities in Efforts, July 2010

3137 Carolina Manzano and Xavier Vives, Public and Private Learning from Prices, Strategic Substitutability and Complementarity, and Equilibrium Multiplicity, July 2010

3138 Axel Löffler, Gunther Schnabl and Franziska Schobert, Inflation Targeting by Debtor Central Banks in Emerging Market Economies, July 2010

3139 Yu-Fu Chen and Michael Funke, Global Warming and Extreme Events: Rethinking the Timing and Intensity of Environmental Policy, July 2010

3140 Lawrence M. Kahn, Labor Market Policy: A Comparative View on the Costs and Benefits of Labor Market Flexibility, July 2010

3141 Ben J. Heijdra, Jochen O. Mierau and Laurie S.M. Reijnders, The Tragedy of Annuitization, July 2010

3142 Erkki Koskela, Outsourcing Cost and Tax Progression under Nash Wage Bargaining with Flexible Outsourcing, July 2010

3143 Daniel Osberghaus and Christiane Reif, Total Costs and Budgetary Effects of Adaptation to Climate Change: An Assessment for the European Union, August 2010

3144 Philip E. Graves, Benefit-Cost Analysis of Environmental Projects: A Plethora of Systematic Biases, August 2010

3145 Sabrina Di Addario and Daniela Vuri, Entrepreneurship and Market Size. The Case of Young College Graduates in Italy, August 2010

3146 Shoshana Amyra Grossbard and Alfredo Marvăo Pereira, Will Women Save more than Men? A Theoretical Model of Savings and Marriage, August 2010 
3147 Jarko Fidrmuc, Time-Varying Exchange Rate Basket in China from 2005 to 2009, August 2010

3148 Ilja Neustadt and Peter Zweifel, Is the Welfare State Sustainable? Experimental Evidence on Citizens' Preferences for Redistribution, August 2010

3149 Marcus Dittrich and Andreas Knabe, Wage and Employment Effects of Non-Binding Minimum Wages, August 2010

3150 Shutao Cao, Enchuan Shao and Pedro Silos, Fixed-Term and Permanent Employment Contracts: Theory and Evidence, August 2010

3151 Ludger Woessmann, Cross-Country Evidence on Teacher Performance Pay, August 2010

3152 Lorenzo C. G. Pozzi, Casper G. de Vries and Jorn Zenhorst, World Equity Premium Based Risk Aversion Estimates, August 2010

3153 Volker Grossmann, Thomas M. Steger and Timo Trimborn, Dynamically Optimal R\&D Subsidization, August 2010

3154 Alexander Haupt, Tim Krieger and Thomas Lange, A Note on Brain Gain and Brain Drain: Permanent Migration and Education Policy, August 2010

3155 António Afonso and Christophe Rault, Long-run Determinants of Sovereign Yields, August 2010

3156 Franziska Tausch, Jan Potters and Arno Riedl, Preferences for Redistribution and Pensions. What can we Learn from Experiments?, August 2010

3157 Martin Kolmar and Andreas Wagener, Inefficient Group Organization as Optimal Adaption to Dominant Environments, August 2010

3158 Kai Carstensen, Klaus Wohlrabe and Christina Ziegler, Predictive Ability of Business Cycle Indicators under Test: A Case Study for the Euro Area Industrial Production, August 2010

3159 Horst Rottmann and Timo Wollmershäuser, A Micro Data Approach to the Identification of Credit Crunches, August 2010

3160 Philip E. Graves, Appropriate Fiscal Policy over the Business Cycle: Proper Stimulus Policies Can Work, August 2010

3161 Michael Binder and Marcel Bluhm, On the Conditional Effects of IMF Program Participation on Output Growth, August 2010

3162 Michael Binder, Qianying Chen, and Xuan Zhang, On the Effects of Monetary Policy Shocks on Exchange Rates, August 2010 